\title{
CHARACTERIZATION OF VALPROIC ACID-INITIATED HOMOLOGOUS RECOMBINATION
}

\author{
by
}

Kevin Sha

A thesis submitted to the Department of Pharmacology and Toxicology in conformity with the requirements for the degree of Masters of Science

Queen's University

Kingston, Ontario, Canada

(August, 2009)

Copyright @Kevin Sha, 2009 


\begin{abstract}
Oxidative stress and histone deacetylase (HDAC) inhibition have been implicated as potential mechanisms in valproic acid (VPA) teratogenicity. Reactive oxygen species (ROS) can target DNA to cause oxidative DNA damage and DNA double strand breaks (DSBs) which can be repaired through homologous recombination (HR). HR is not an error free process and can result in detrimental genetic changes. In the present study, we evaluated the potential role of HDAC inhibition in VPA-initiated HR. HDAC inhibition may indirectly alter repair activity or cause DNA DSBs which initiates repair.

The first objective was to investigate the ability of VPA to cause HDAC inhibition in the Chinese hamster ovary $(\mathrm{CHO}) 33$ cell line. As a consequence of HDAC inhibition, an increase in acetylated histone $\mathrm{H} 3$ and $\mathrm{H} 4$ protein levels were observed after 10 to $24 \mathrm{hr}$ exposure to $5 \mathrm{mM}$ VPA.

Secondly, to investigate whether VPA affects the activity of DNA DSB repair, CHO 33 cells were transfected with either the endonuclease I-Sce 1 plasmid to induce a site specific DSB, or the empty plasmid, pGem. However, no increase in the difference in HR between VPA and media exposed I-Sce1 transfected cells compared to cells transfected with pGem was observed, which suggests that VPA does not affect DNA repair activity.

Thirdly, to determine if VPA increases susceptibility to DNA DSBs, immunocytochemistry revealed an increase in the number of $\boldsymbol{\gamma}-\mathrm{H} 2 \mathrm{AX}$ foci after 10 to 24 hr exposure to VPA. To determine if oxidative stress plays a role in mediating VPAinduced DNA DSBs, another recombination study was carried out in which cells were
\end{abstract}


pretreated with $400 \mathrm{U} / \mathrm{ml}$ of PEG-catalase, an antioxidant, prior to VPA treatment. The observed protective effect of PEG-catalase against VPA-induced HR and the generation of intracellular ROS by VPA suggest ROS may also play a role in VPA-initiated HR. ROS can cause oxidative DNA damage which can lead to DNA DSBs. However, in our DNA oxidation study, no increase in the oxidized nucleosides, 8-hydroxy-2'-

deoxyguanosine and 5-hydroxycytosine was observed after VPA treatment. These studies suggest that HDAC inhibition and ROS signalling may play roles in DNA maintenance and cell cycle arrest in initiating DNA DSBs and HR repair. 


\section{Co-Authorship}

This research was conducted by the candidate Kevin Sha, under the supervision of Dr.

Louise M. Winn. 


\section{Acknowledgements}

First and foremost, I would like to thank my supervisor, Dr. Louise M. Winn for her guidance and support. Thank you for giving me the opportunity to be part of your lab. It has been a great privilege working with you.

To the current and past members of the Winn lab, thank you for providing a "unique" working environment as well as your guidance and assistance. It was a pleasure to have worked alongside all of you and making my time in the lab an interesting and memorable experience.

I also wish to thank the faculty, administration and students at the Department of Pharmacology and Toxicology for their assistance and support. I want to acknowledge the students in Dr. Catherine M. Cahill's lab for their help in the immunocytochemistry experiment and also Neeraj Gupta from Dr. Thomas E. Massey's lab for his help in the DNA oxidation experiment.

To my committee members, Dr. Thomas E. Massey and Dr. Kanji Nakatsu, I am grateful for your helpful insights and advice towards my research.

Many thanks to my friends back home for their continued support and encouragement.

Last but not least, I want to thank my family for their love, encouragement and support throughout these past two years. 


\section{Table of Contents}

Abstract............................................................................................................................. ii

Co-Authorship ....................................................................................................................... iv

Acknowledgements ..................................................................................................................v

Table of Contents.......................................................................................................... vi

List of Figures.................................................................................................................. viii

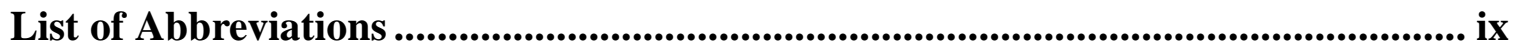

Chapter 1 ...........................................................................................................................1

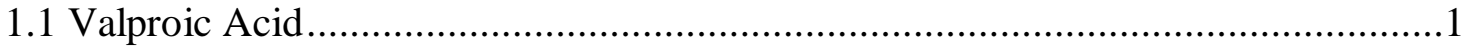

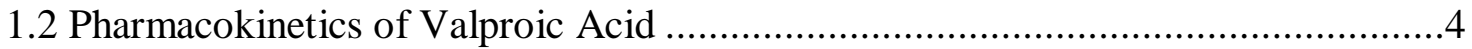

1.3 Serious Complications Associated with Valproic Acid Treatment ......................... 4

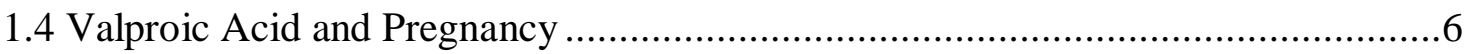

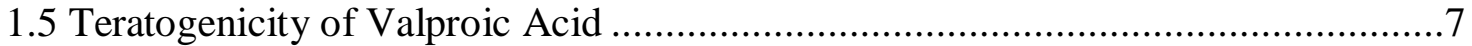

1.6 Bioactivation to Reactive Metabolites in Chemical Teratogenesis ..........................8

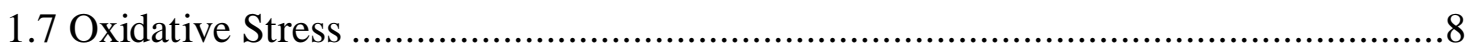

1.8 Oxidative Stress in Valproic Acid-Induced Teratogenesis......................................12

1.9 Oxidative DNA Damage and DNA Double-Strand Breaks ..................................13

1.10 Repair of DNA Double-Strand Breaks........................................................... 14

1.11 Homologous Recombination and Genomic Instability ………...........................16

1.12 Valproic Acid-Initiated Homologous Recombination .........................................18

1.13 Inhibition of Histone Deacetylase as a Mechanism of Teratogenesis ...................19

1.14 Research Rationale, Hypothesis and Objectives................................................24

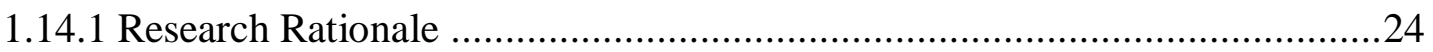

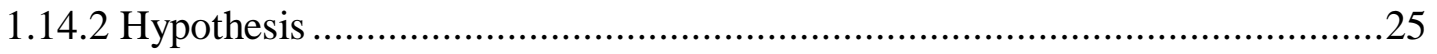

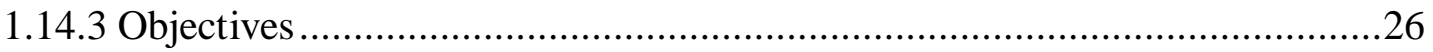

Chapter 2 Materials and Methods ............................................................................28

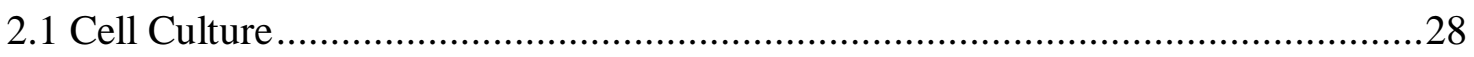

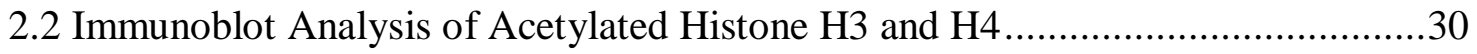

2.2.1 Treatment and Sample Preparation..............................................................30 
2.2.2 SDS-PAGE and Immunoblotting 30

2.3 Double-Strand Break-Induced Recombination Assay ....................................31

2.4 Double-Strand Break-Induced Recombination Assay with Trichostatin A ...........32

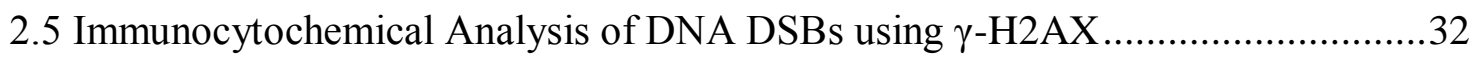

2.6 Double-Strand Break-Induced Recombination Assay with Pretreatment with PEG-

Catalase .33

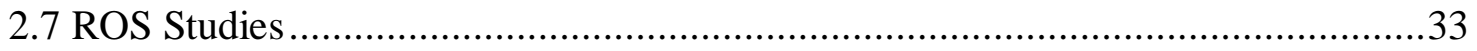

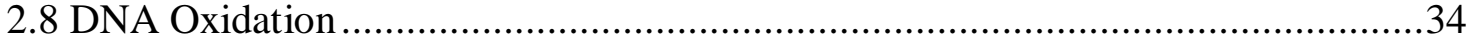

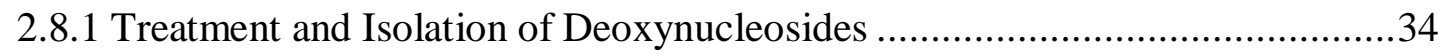

2.8.2 High Pressure Liquid Chromatography with Electrochemical Detection.........35

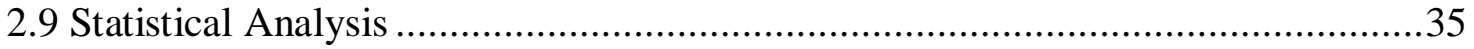

Chapter 3 Results ...........................................................................................................36

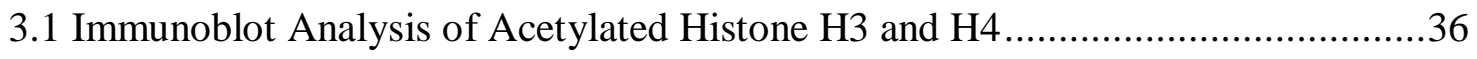

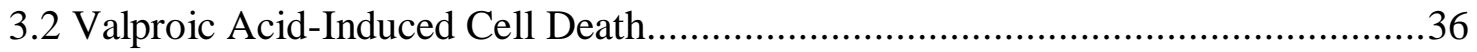

3.3 Valproic Acid-Induced Homologous Recombination.......................................39

3.4 Comparative study of Trichostatin A and Valproic Acid Initiated Homologous

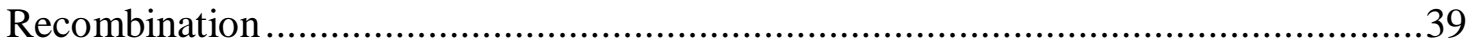

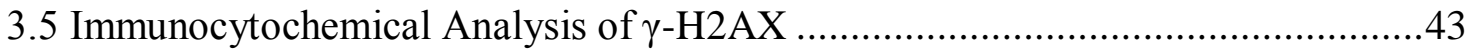

3.6 The Effects of PEG-Catalase Pretreatment on Valproic Acid-Initiated Homologous

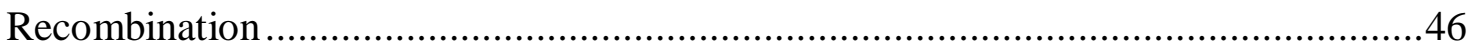

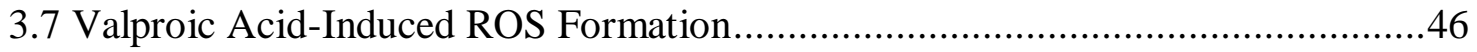

3.8 Oxidative DNA Damage as a Result of Valproic Acid-Induced ROS ..................49

Chapter 4 Discussion .......................................................................................52

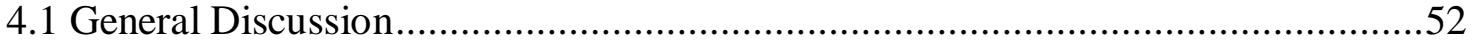

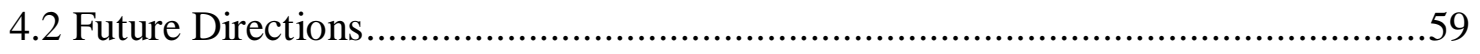

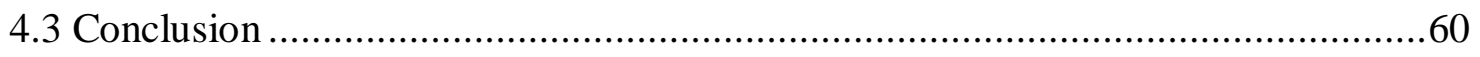

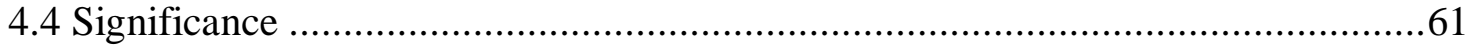

References ...........................................................................................62 


\section{List of Figures}

Figure 1.1 The molecular structure of valproic acid (2-propylpentanoic acid)..............2

Figure 1.2 Postulated biochemical pathways of chemical teratogenesis.......................9

Figure 1.3 Pathways in the formation and detoxification of reactive oxygen species.....11

Figure 1.4 Model of DNA double strand repair by the non-homologous end joining and

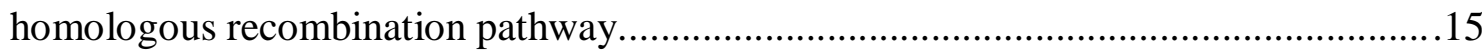

Figure 1.5 Mechanisms of erroneous homologous recombination repair...............17

Figure 1.6 Valproic acid-induced homologous recombination......................20

Figure 1.7 Oxidative stress as a mechanism of valproic acid-induced homologous recombination.

Figure 1.8 Regulation of transcriptional activity through post-translation acetylation of histones. .23

Figure 1.9 Schematic of the hypothesized mechanism of Valproic acid-initiated homologous recombination. .27

Figure 2.1 Recombination reporter substrate. .29

Figure 3.1 Valproic acid-induced hyperacetylation of histone $\mathrm{H} 3$ and $\mathrm{H} 4 \ldots \ldots \ldots \ldots . . . . .37$

Figure 3.2 Valproic acid and transfection induced-cell death........................

Figure 3.3 Valproic acid-induced homologous recombination...................................40

Figure 3.4 Valproic acid does not affect homologous recombination repair activity......41

Figure 3.5 Valproic acid and trichostatin A-induced cell death.................................42

Figure 3.6 Valproic acid and trichostatin A-induced homologous recombination...........44

Figure 3.7 Valproic acid-induced DNA double strand breaks....................................45

Figure 3.8 Valproic acid and polyethylene glycol-catalase induced-cell death...............47

Figure 3.9 Polyethylene glycol-catalase protection against Valproic acid-induced

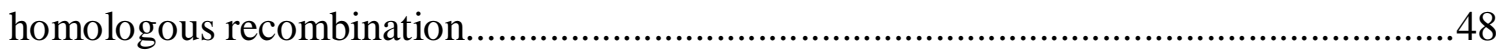

Figure 3.10 Valproic acid-induced reactive oxygen species formation.........................50

Figure 3.11Valproic acid-induced DNA oxidative damage ........................................51 


\section{List of Abbreviations}

2'-dG

5-OH-C

8-OH-2'-dG

$\gamma-\mathrm{H} 2 \mathrm{AX}$

ANOVA

AP

ATM

BER

BSA

$\mathrm{CHO}$

CM-H2DCFDA

DSB

GABA

G418

GSH

GADD $45 \alpha$

HAT

HDAC

HR

$\mathrm{LOH}$

NTD

NHEJ

NER

OCT-1

PBS

PEG

ROS

SDS

SSA

SOD

TSA

VPA 2'-deoxyguanosine

5-hydroxycytosine

8-hydroxy-2'-deoxyguanosine

Gamma-H2AX (phosphorylation of histone H2AX at serine 139)

analysis of variance

apurinic/apyrimidinic

ataxia telangiectasia-related

base excision repair

bovine serum albumin

Chinese hamster ovary

5-(and-6)-chloromethyl-2-7-dichlorodihydrofluorescein diacetate double strand break

gamma-aminobutyric acid

Geneticin

glutathione

growth arrest and DNA damage-45 alpha

histone acetyl-transferase

histone deacetylase

homologous recombination

loss of heterozygosity

neural tube defect

non-homologous end-joining

nucleotide excision repair

octamer binding transcription factor 1

phosphate buffer saline

polyethylene glycol

reactive oxygen species

sodium dodecyl sulfate

single-strand annealing

superoxide dismutase

trichostatin A

valproic acid 


\section{Chapter 1}

\section{Introduction}

\subsection{Valproic Acid}

Valproic acid (VPA) is a simple eight carbon branched-chain carboxylic acid (Figure 1.1) that was first synthesized in 1882 by Burton as an inert solvent for organic compounds (Burton, 1882). Nearly a century later, Eymard and colleagues serendipitously discovered the anticonvulsant activity of VPA (Meunier et al., 1962) and since its introduction in North America in 1978, VPA has been clinically used as a first line antiepileptic drug in the management of both partial and generalized seizure disorders (Pinkston and Walker, 1997). In addition to its use as an antiepileptic agent, VPA has also been approved for the treatment of bipolar affective disorders, migraine prophylaxis and treatment for neuropathic pain (Russell, 2007). However, despite more than 30 years of clinical use, the mechanism of its therapeutic effects remains unclear.

Several mechanisms of action of VPA have been postulated which may explain the broad spectrum of activity of VPA. The anticonvulsant effect of VPA is thought to be mediated through changes in gamma-aminobutyric acid (GABA)-ergic functions in the brain by increasing both the synthesis and release of GABA (Owens et al., 2003; Perucca, 2002). Several studies also suggest VPA may exert a direct inhibitory effect on 


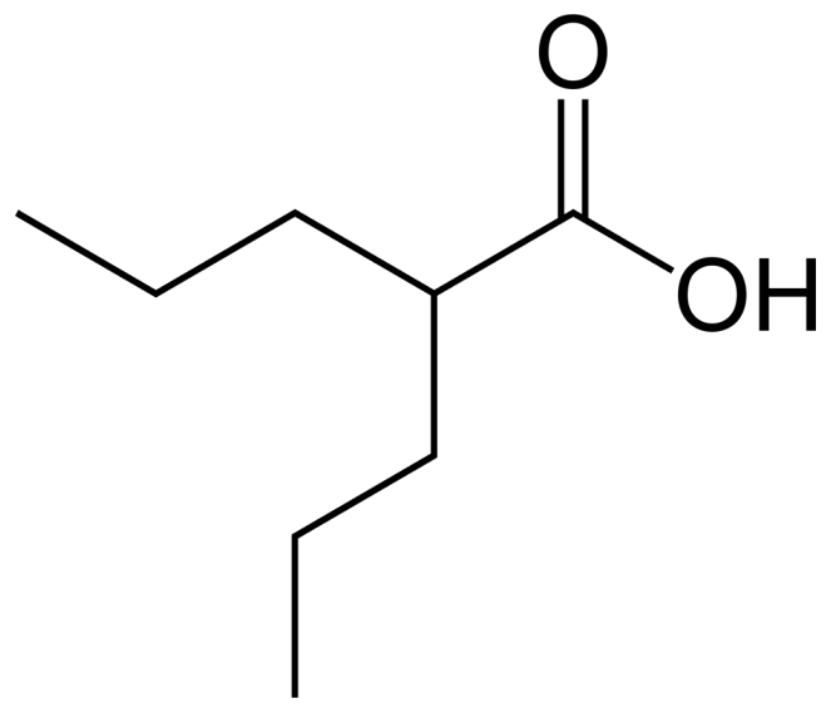

Figure 1.1 The molecular structure of valproic acid (2-propylpentanoic acid). 
voltage-gated $\mathrm{Na}^{+}$channels, suppressing high-frequency firing of hippocampal neurons (McLean and MacDonald, 1986; Van den Berg et al., 1993). VPA may also act as a noncompetitive inhibitor of cortical myo-inositol-1-phosphate synthase, an enzyme that is responsible for the synthesis of the substrate for inositol monophosphate (Shaltiel et al., 2004). The resulting inositol depletion may mediate the antimanic effects of VPA (Silverstone et al., 2005). For protection against migraines, VPA has been shown to be a direct non-competitve inhibitor of brain microsomal long chain fatty acyl-CoA and inhibition of this enzyme subsequently leads to a decrease in prostaglandin production (Bazinet et al., 2006).

More recently, research has been focused on the anticancer effects of VPA. Inhibition of histone deacetylase (HDAC) by VPA has been shown to reactivate genes involved in cell cycle progression, differentiation, and apoptosis to cause cell cycle arrest, differentiation, and/or apoptosis of cancer cells (Abdul and Hoosein, 2001; Kawagoe et al., 2002; Olsen et al., 2004). Hyperacetylation of histones and relaxation of chromatin by VPA may also enhance the cytotoxicity of drugs that target DNA such as doxorubicin (Catalano et al., 2006). Currently, VPA is being examined in numerous clinical trials as an anticancer agent for different leukaemias and solid tumour entities (Vavrova et al., 2005). In addition, VPA's combined effects with other antineoplastic agents are also being evaluated (Duenas-Gonzalez, 2008). 


\subsection{Pharmacokinetics of Valproic Acid}

Following oral administration of the drug, VPA is rapidly absorbed from the gastrointestinal tract, with peak serum levels occurring 1 to 4 hours after ingestion (Klotz and Antonin, 1977). VPA is a weak acid with a pKa of 4.7 (Sztajnkrycer, 2002). Under physiological conditions, it is completely ionized so it is mostly bound to serum proteins in the circulation. The therapeutic level of VPA ranges between 50 and $150 \mathrm{mg} / \mathrm{L}$ (Sztajnkrycer, 2002) and concentrations above $150 \mathrm{mg} / \mathrm{L}$ can saturate protein binding sites resulting in an increase in unbound drug which can lead to toxicity. VPA undergoes extensive metabolism in the liver via direct glucuronidation, mitochrondrial $\beta$ oxidation, and cytosolic $\omega$ and $\omega_{1}$ oxidation with less than $3 \%$ of the drug excreted unchanged in the urine (Franssen et al., 1999; Jakobs and Loscher, 1978; Nau and Wittfoht, 1981). Glucuronide conjugation and mitochrondrial $\beta$ oxidation are the major pathways of metabolism in the liver while cytosolic $\omega$ and $\omega_{1}$ oxidation provide only minor contributions (Tatsuhara et al., 1987). During elimination, VPA follows first-order kinetics (Nau and Loscher, 1984), where serum half-lives range from 8 to 21.5 hours with a mean half-life of 12.2 ( + or -$) 3.7$ hours at therapeutic serum concentrations (Sztajnkrycer, 2002).

\subsection{Serious Complications Associated with Valproic Acid Treatment}

Although VPA is well tolerated, rare and serious complications may occur in patients receiving chronic VPA treatment, including haemorrhagic pancreatitis 
(Asconape et al., 1993; Camfield et al., 1979), bone marrow suppression (Kishi, et al., 1994; Williams et al., 2008) and hepatotoxicity (Konig et al., 1999; Scheffner et al., 1988).

In VPA-induced hepatoxicity, approximately $30-50 \%$ of patients on chronic treatment show elevated serum aminotransferases in the first months of therapy (Bryant and Dreifuss, 1986). However this type I dose-dependent liver toxicity is transient and toxicity is usually resolved if the drug is discontinued or treatment can continue with close monitoring of liver function tests (Lheureux et al., 2005). Type II or idiosyncratic hepatotoxicity, is a rare side effect of VPA that can lead to hepatic failure and death (Andersen and Ritland, 1995; Scheffner et al., 1988; Zimmerman and Ishak, 1982). The pathogenesis of this rare form of VPA hepatotoxicity is still unclear, but the observation of microvesicular steatosis which may be followed by necrosis (Scheffner et al., 1988, Zafrani and Berthelot, 1982), is consistent with the disturbance in mitochrondrial function (Fromenty and Pessayre, 1997) and fatty acid metabolism (Kossak et al, 1993). The generation of reactive metabolites has been postulated as one of the many mechanisms of VPA-induced idiosyncratic hepatotoxicity. Reactive metabolites such as 4-ene-VPA and (E)-2,4-diene-VPA that are generated by cyctochrome P450 and mitochrondrial $\beta$-oxidative respectively have been shown to be potent inducers of microvesicular steatosis in rats (Kesterson et al, 1984). Other studies also suggest that both VPA and its metabolites, including 4-en-VPA-CoA, may interfere with fatty acid metabolism by direct inhibition of specific enzymes involved in the process to cause 
mitochrondial dysfunction (Ponchault et al., 1992; Silva et al., 2001a). Several other mechanisms that have been proposed to explain VPA-induced idiosyncratic hepatoxicity include: carnitine deficiency (Coulter, 1984), drug-induced coenzyme A deficiency (Silva et al., 2001b), hyperammonemia (Powell-Jackson et al., 1984), underlying inborn error of metabolism (Kottlors et al., 2001; Papadimitriou. and Servidei, 1991) and oxidative stress as a result of compromised free radical scavenging activity (Chang and Abbot, 2006).

\subsection{Valproic Acid and Pregnancy}

One of the major contraindications for the use of VPA is pregnancy. VPA is a known teratogen and women who take VPA during the first trimester of pregnancy have more than 2.5 times the risk of having offspring with congenital malformations compared to the general population in a dose dependent manner (Koren et al., 2006). VPA can also affect the developing brain and nervous system in the second and third trimester to cause functional and behavioral defects (Adad et al, 2004; Eriksson et al., 2005). Although exposure can be avoided by discontinuation of the drug, potential physical injuries can be harmful to the fetus as a result of uncontrolled epileptic seizures (Battino and Tomson, 2007). Certain types of seizures may directly cause harm to the fetus including convulsive seizures that can lead to fetal bradycardia (Teramo et al., 1979) and induce lactic acidosis which can be transferred to the fetus (Hiilesmaa et al., 1985). Therefore proper management of the risks associated with uncontrolled seizures and potential birth defects induced by VPA is required for women with epilepsy considering 
pregnancy. The common strategy for the use of antiepileptic drugs during pregnancy is monotherapy at the lowest effective dose since polytherapy has also been shown to increase the risk of malformations (Battino and Tomson, 2007).

\subsection{Teratogenicity of Valproic Acid}

Although VPA is ionized under physiological conditions, it can easily cross the placenta and fetal concentration can exceed maternal concentration (Dickinson et al., 1979; Nau et al., 1981) through decreased albumin in maternal serum causing an increase in free drug and an increase in protein binding of VPA in fetal serum (Froescher et al., 1984). Recently, an active transport system including a $\mathrm{H}^{+}$-coupled monocarboxylate transporter in the brush-border membrane of trophoblast cells has been shown to transport VPA across the placenta (Nakamura et al., 2002). Since chronic VPA treatment extends throughout pregnancy, the fetus may constitute a site in which VPA may accumulate during development and at the time of birth, levels of VPA and its metabolites in cord serum have been shown to exceed maternal serum concentrations (Nau et al., 1981).

Among the various forms of birth defects, neural tube defects (NTDs) (Koren et al., 2006) and cardiac (Sodhi et al., 2001) and limb anomalies (Holmes, 2002) are considered the major malformations associated with in utero VPA exposure. Distinct facial features (Moore et al., 2000), developmental delays and cognitive deficits are also associated with the use of VPA during pregnancy (Adad et al, 2004, Eriksson et al., 
2005). These various birth defects present in children are clinically characterized as fetal valproate syndrome (Kini, 2006). The full mechanism by which VPA induces these developmental toxic effects however, is not known.

\subsection{Bioactivation to Reactive Metabolites in Chemical Teratogenesis}

For xenobiotics, including many antiepileptic drugs, the generation of highly toxic reactive intermediates by embryonic bioactivation is thought to play a major role in chemical teratogenesis (Winn and Wells, 1997; Parman et al., 1998). The parent drug (proteratogen) which is relatively nontoxic can be bioactivated by embryonic cytochrome P450s, prostaglandin $\mathrm{H}$ synthase and lipoxygenases to highly toxic reactive intermediates to cause damage during development (Wells et al., 1997, Figure 1.2). However, detoxification pathways including maternal proteratogen elimination, embryonic detoxification of reactive intermediates, cytoprotection pathways for detoxifying reactive oxygen species and repair of damaged cellular macromolecules are in place to counteract the potential developmental toxicity that can occur (Wells et al., 1997). Therefore the teratogenic outcome depends on the balance of these competing pathways of bioactivation and detoxification.

\subsection{Oxidative Stress}

Oxidative stress as a consequence of bioactivation of parent compounds has been implicated in a number of teratogens (Amini et al., 1996; Hansen et al., 2002; Winn and 


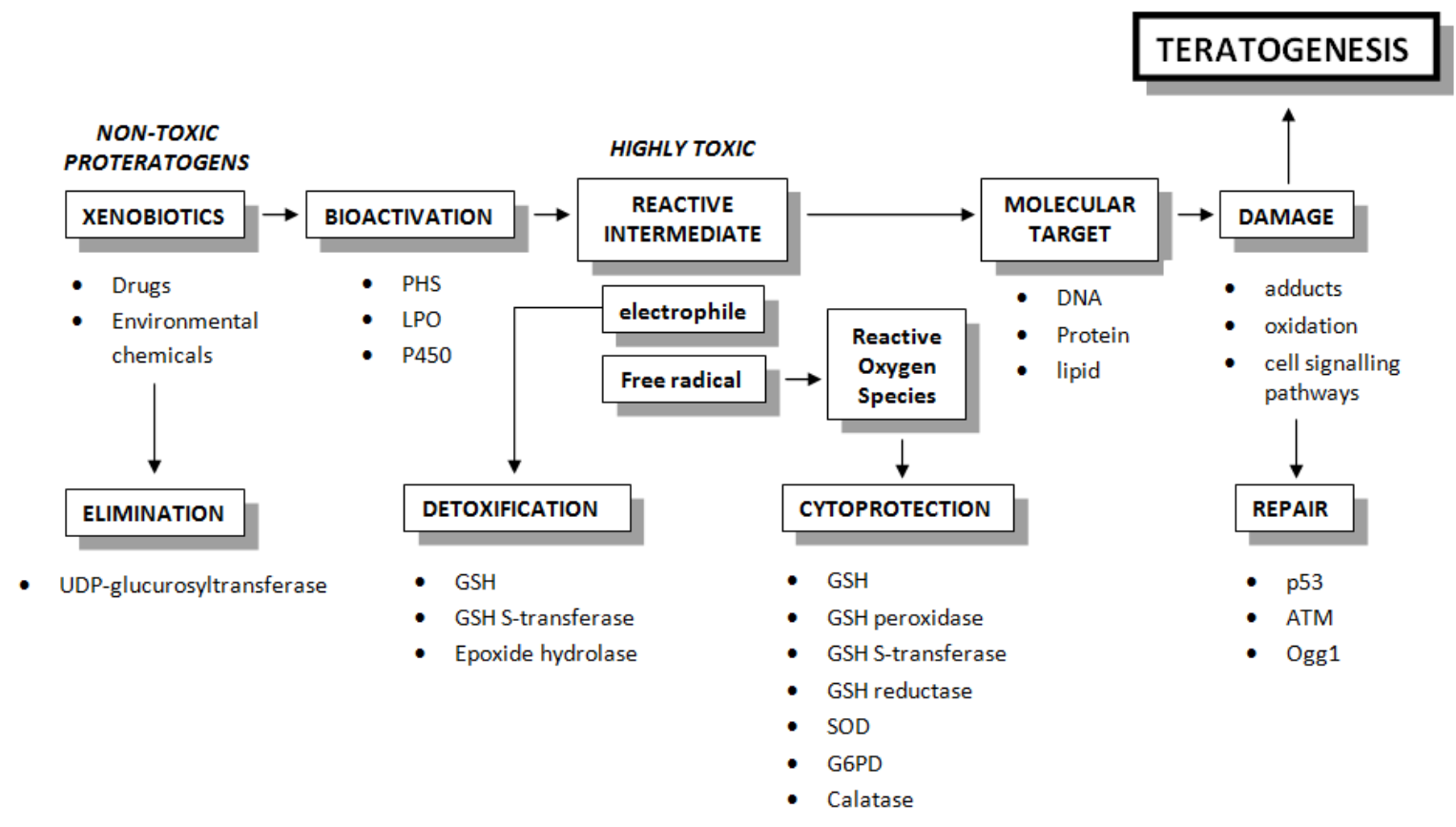

Figure 1.2 Postulated metabolic biochemical pathways of chemical teraogenesis.

Teratogenic outcome depends on the balance between embryonic bioactivation of proteratogens to reactive intermediate metabolites and maternal elimination and embryonic protective pathways. Abbreviations: ATM, ataxia telangiectasia mutated; G6PD, glucose-6-phosphate dehydrogenase; GSH, glutathione; LPO, lipoxygenase; PHS, prostaglandin $\mathrm{H}$ synthase; Ogg1, oxoguanine glycosylase 1; P450, cytochrome P450 (CYP); SOD, superoxide dismutase; UDP, uridine diphosphate (modified from Wells et al., 2005). 
Wells, 1999). Oxidative stress occurs when there is insufficient capacity to remove free radical intermediates resulting in excessive levels of these highly reactive and short lived species. These free radical intermediates can initiate the formation of a number of reactive oxygen species (ROS) including superoxide anion $\left(\mathrm{O}_{2}{ }^{\circ}\right)$ and hydrogen peroxide $\left(\mathrm{H}_{2} \mathrm{O}_{2}\right)$ which can react to form the highly reactive hydroxyl radical $(\cdot \mathrm{OH})$ that can oxidize cellular macromolecules including proteins, lipids and DNA (Wells et al., 1997; Figure 1.3). In addition to causing irreversible oxidative damage, excess ROS can also selectively oxidize sulfhydryl groups of specific cysteine residues on proteins to cause dysregulation of endogenous ROS-mediated signal transduction to alter cellular functions (Hansen, 2006). To counteract potential oxidative damage, cells utilize antioxidants (including vitamin $\mathrm{C}$, vitamin $\mathrm{E}$ and glutathione $(\mathrm{GSH})$ ) and antioxidant enzymes to remove ROS. Superoxide dismutase (SOD) can catalyze the dismutation of superoxide into oxygen and hydrogen peroxide while catalase can break down hydrogen peroxide into water (Wells et al., 1997). Glutathione peroxidase can also convert hydrogen peroxide into water by oxidizing glutathione to form glutathione disulfide (Wells et al., 1997). These two antioxidant enzymes play a crucial role in removing hydrogen peroxide before it can be converted to the highly reactive hydroxyl radical. Unfortunately, the expression and activity of these antioxidant enzymes are very low in the developing embryo (Wells et al., 2005). Although SOD, catalase and GSH peroxidase activity increase with gestational age, the embryo is susceptible to oxidative stress during early stages of development when organogenesis is taking place (Ornoy, 2007). 


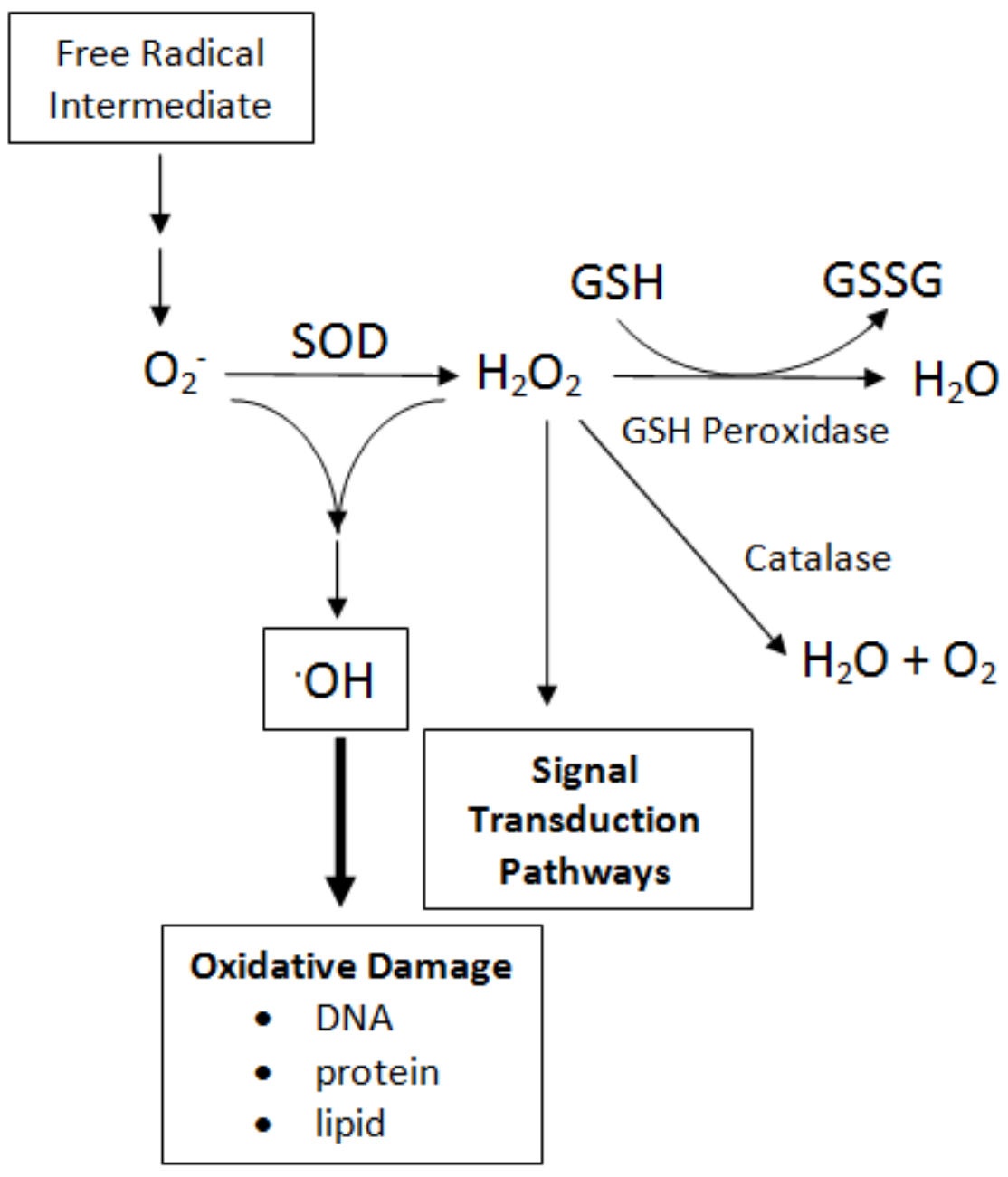

Figure 1.3 Pathways in the formation and detoxification of reactive oxygen species. Free radical intermediates can react with oxygen to produce superoxide anion which can be converted to hydrogen peroxide by superoxide dismutase. Catalase and GSH peroxidase subsequently break down hydrogen peroxidase into water. If hydrogen peroxide is not eliminated, it can react with superoxide anion in the presence of iron to form the highly reactive hydroxyl radical to cause oxidative damage. Abbreviations: GSH, glutathione; GSSG, glutathione disulfide; SOD, superoxide dismutase (modified from Wells et al., 1997). 


\subsection{Oxidative Stress in Valproic Acid-Induced Teratogenesis}

Similar to other traditional antiepileptic drugs and xenobiotics, oxidative stress has also been implicated in VPA-induced teratogenesis. Several studies have demonstrated the ability of VPA to induce oxidative stress through biotransformation into reactive metabolites (Tabatabaei et al., 1999), alterations in glutathione homeostasis (Seckin et al., 1999) or depletion of cofactors required for antioxidant activity (Graf $e t$ al., 1998). In an in vitro model, microsomal-dependent generation of hydrogen peroxide from VPA was shown to readily cross cell membranes and react with iron to produce highly reactive hydroxyl free radicals (Tabatabaei et al., 1999). Subsequent treatment with the antioxidant catalase prevented against VPA-induced cytotoxicity. During development, pre-treatment with the free radical scavenger vitamin $\mathrm{E}$ has been shown to decrease VPA-induced NTDs and attenuate malformations in the ribs of mice (Baran et al., 2005), implicating the role of VPA-induced ROS in the involvement of birth defects. Additionally, VPA has been observed to inhibit cardiomyocyte differentiation of embryonic stem cells through an increase in ROS production, and this differentiation was restored with the administration of vitamin $\mathrm{E}$ ( $\mathrm{Na}$ et al., 2003). In a clinical setting, oxidative stress has also been detected through the urinary biomarker $15-\mathrm{F}_{2 t}$-isoprostane, a prostaglandin-like compound produced by free radical catalyzed lipid peroxidation of arachidonic acid in children taking normal therapeutic doses of VPA (Michoulas et al., 2006). Similarly, elevated levels of malondialdehyde, a product of membrane lipid peroxidation, have been reported in adults receiving VPA (Hamed et al., 2004). 


\subsection{Oxidative DNA Damage and DNA Double-Strand Breaks}

As indicated earlier, ROS can also target DNA to cause oxidative DNA damage. ROS, especially hydroxyl radicals, can cause a variety of different types of DNA damage including abasic sites, oxidization of bases, DNA-protein and DNA-DNA crosslinks, and single and double strand breaks (Kohen and Nyska, 2002). Damage to single nucleotides including abasic sites and oxidized bases can be repaired through the base excision repair (BER) system. The damaged base is first excised by a bifunctional DNA glycosylase with apurinic/apyrimidinic (AP) lyase activity, such as 8-oxoguanine DNA glycosylase that cleaves the $\mathrm{N}$-glycosylic bond between the damaged base and deoxyribose, leaving an AP site on the DNA backbone (Bjoras et al., 1997; Rosenquist et al., 1997). The sugar and phosphate backbone are then removed by class II AP endonuclease (Hill et al., 2001) and the repair is completed by polymerase and ligase activity (Lindahl and Wood, 1999). For larger and bulkier types of DNA damage that cause a helical distortion such as DNA-protein adducts, damage is repaired by nucleotide excision repair (NER), although NER is also capable of repairing single nucleotide damage (Nouspikel, 2009). NER is a more complex repair system than BER, and instead of removal of one nucleotide, NER removes oligonucleotides (25-30 nucleotides) during repair (Nouspikel, 2009). However if two oxidized bases are in close proximity of each other on opposite strands, AP endonuclease activity from BER or NER can cleave the DNA backbone of both strands resulting in a DNA double-strand break (DSB; Pfeiffer et al., 2000). Additionally, single strand breaks caused by oxidative damage repair through BER or 
NER can be converted to DSBs during replication where there is a collapse of the replication fork (van den Bosch et al., 2002). DNA DSBs are the most genotoxic type of DNA damage since there is often no complementary DNA template for repair unlike BER and NER which utilize the undamaged complimentary strand as a template for repair (Lindahl and Wood, 1999; Nouspikel, 2009).

\subsection{Repair of DNA Double-Strand Breaks}

In the absence of a complementary DNA template for repair, DNA DSBs are repaired through non-homologous end-joining (NHEJ). This repair pathway involves a number of proteins that rejoins the two DNA strands together in a stepwise manner. The process begins when proteins are recruited to the free ends of the DNA. A molecular bridge is formed between the two DNA ends and processing of the free ends occurs to allow for ligation of the DNA ends (Pardo et al., 2009). As a consequence of processing DNA ends, genetic information can be lost from the site of damage, which can cause gene deletions or insertions leading to genomic instability (van den Bosch et al., 2002). In mammalian cells, DNA DSBs can also be repaired through homologous recombination (HR). Unlike NHEJ, HR requires homologous sequences for sister chromatid or homologous chromosomes as a template for repair (Pardo et al., 2009; Figure 1.4). However if the DNA template used for repair is not identical to the original DNA sequence present at the DSB, HR repair can also lead to genomic changes including loss 


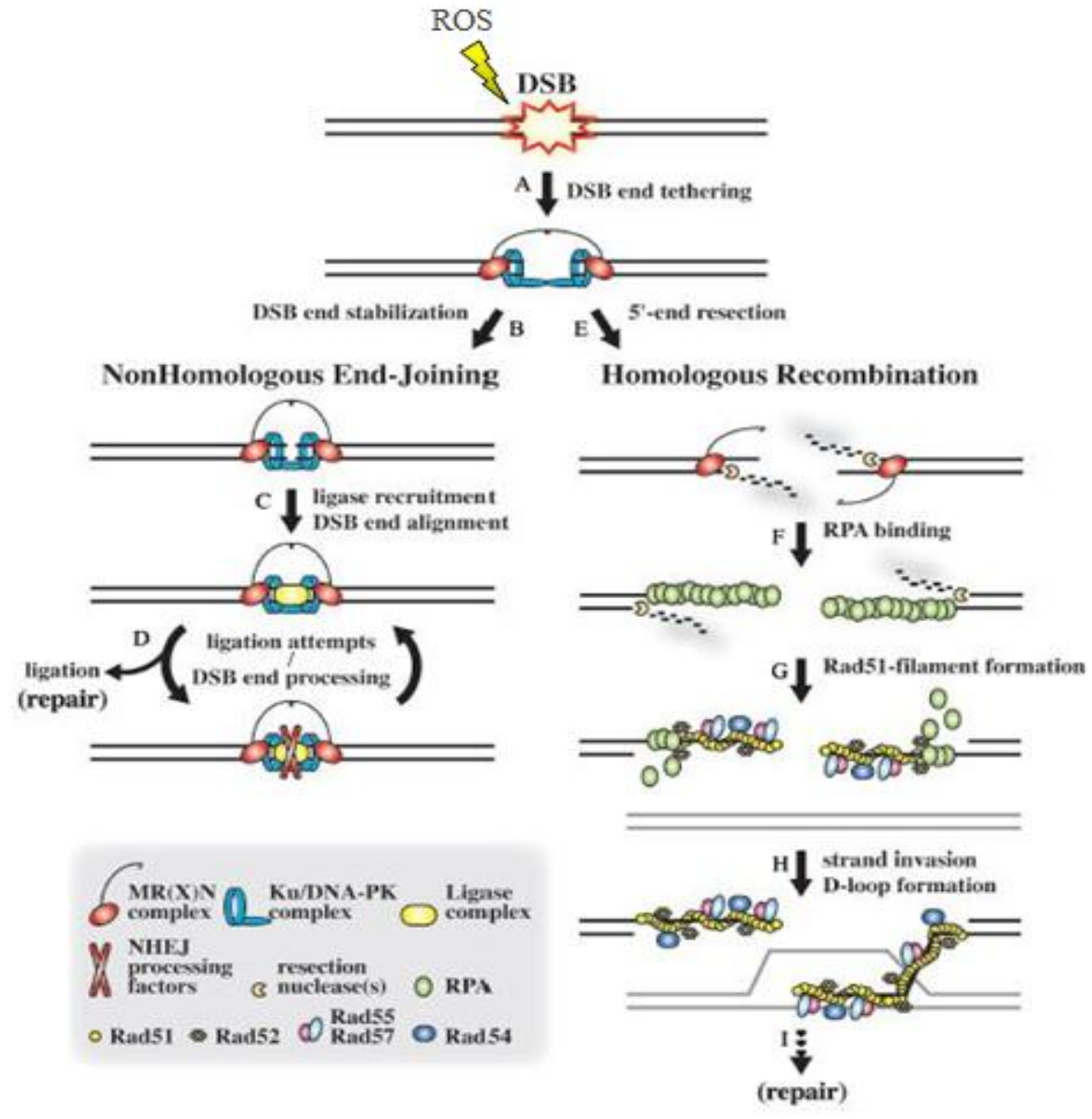

Figure 1.4 Model of DNA double strand break repair by the non-homologous end joining and homologous recombination pathway.

At the site of the DNA DSB, (A) DSB ends are tethered by $\mathrm{MR}(\mathrm{X}) \mathrm{N}$ and Ku/DNA-PK complexes. In NHEJ, (B) the DSB is further stabilized by MR(X)N and Ku/DNA-PK. (C) These proteins recruit the ligase complex to align the DSB ends. (D) DSB ends are then ligated or process prior to ligation. In HR, 5' DSB ends are resected by MR(X)N and other nucleases. (F) RPA binds to the single-stranded overhangs generated by resection. (G) RPA-coated single-stranded DNA is a substrate for Rad51-filament formation involving Rad52, Rad55-57 and Rad54. (H) Homology search and strand invasion by Rad51-filament leads to the formation of a D-loop. (I) Following D-loop formation, repair is continued through different HR pathways. Homologous template is represented by the grey lines (modified from Pardo et al., 2009). 
of heterozygosity (LOH), gene deletions and amplification and translocations (Reliene et al., 2007).

In contrast to NHEJ which can function throughout the cell cycle particularly in G1 phase (Shrivastav et al., 2007), HR is consider to be active in late S/G2 phase since it requires homologous sequences elsewhere in the genome for repair (Shrivastav et al., 2007). Even though each pathway is used preferably in different times of the cell cycle, they are not independent of each other since both pathways are initiated in response to DNA DSBs and there is compensatory activity if one repair pathway is impaired (Allen et al., 2002; Richardson and Jasin, 2000).

\subsection{Homologous Recombination and Genomic Instability}

Although HR is considered to be relatively error free compared to NHEJ, errors can be introduced after repair (Figure 1.5). Homology-dependent pathways can be divided into conservative and non-conservative processes (Pfeiffer et al., 2000). The conservative process utilizes genetic sequences on sister chromatid and homologous chromosome to yield two intact copies (Pfeiffer et al., 2000). A gene conversion event can occur in the conservative process where the genetic sequence of the damaged allele is converted to the donor allele after repair (Bishop and Schiesti, 2003). The loss of the original allele can lead to LOH (Bishop and Schiesti, 2003). In the non-conservative process, genetic sequences are lost as a result of repair. Non-conservative repair occurs through single-strand annealing (SSA) and crossover events (Bishop and Schiesti, 2003; 


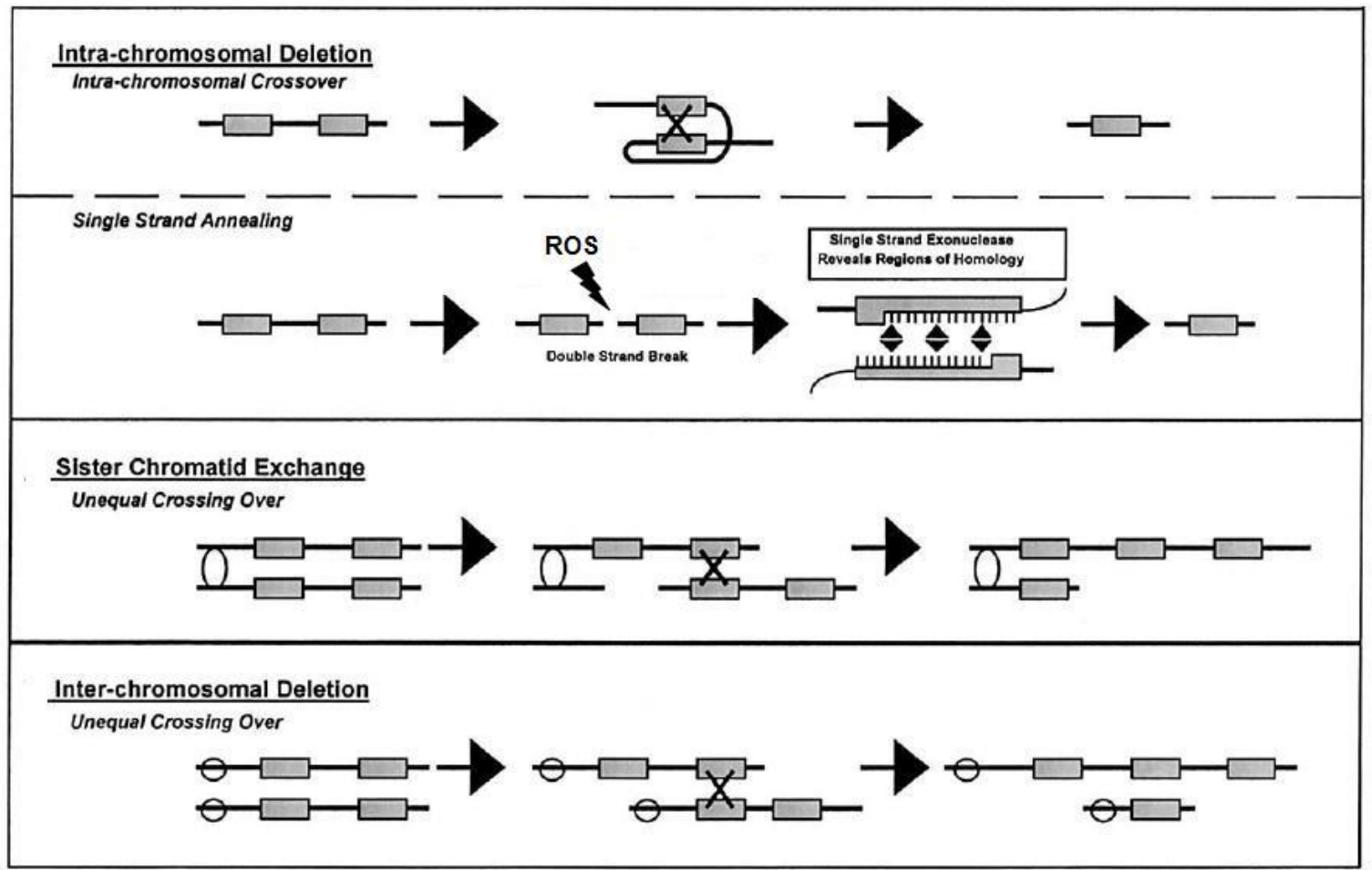

Figure 1.5 Mechanisms of erroneous homologous recombination repair.

Intra-chromosomal deletion can occur during intra-chromosomal crossover where a DNA break allows for strand exchange and recombination between the two strands. Genetic information can also be lost during single strand annealing when DNA is resected to allow for annealing between homologous sequences of the DSB ends. Misalignment of homologous sequences can cause unequal crossover events leading to duplication on one sister chromatid/chromosome and a deletion on the other chromatid/chromosome. The "X" represents a crossover event and the black lines represent double-stranded DNA (modified from Bishop and Schiesti, 2003). 
Figure 1.5). In SSA, single strand exonucleases degrade both ends of the DNA until homology is found between the two ends. Annealing of the DNA ends occurs between the homologous sequences from the two DNA ends. Crossover events can also cause intra-chromosomal deletions. During sister chromatid or homologous chromosome exchange, interchromatid deletion can occur as a result of unequal crossover events between misaligned homologous regions (Bishop and Schiesti, 2003). Unequal exchange can produce deletions on one chromatid/chromosome and duplications at the region on the other chromatid/chromosome (Bishop and Schiesti, 2003, Figure 1.5).

It is not surprising therefore, that genomic instability as a result of erroneous HR repair has been postulated to play a role in carcinogenesis. Many human tumors are characterized by a wide variety of genome rearrangements including deletions, translocations, duplications and LOH (Bishop and Schiesti, 2003; Knudson, 2001). In addition, increased frequencies of HR have also been found in cancer cells and cancerprone genetic diseases including Bloom and Werner syndromes as well as Fanconi anemia (Reliene et al., 2007). Interestingly, developmental defects including short stature, distinct facial features and skeletal defects also manifest in individuals who have these genetic diseases (German, 1995; Fukuch, 1989; Joenje and Patel, 2001).

\subsection{Valproic Acid-Initiated Homologous Recombination}

To determine if VPA can induce HR as a result of oxidative DNA damage, a previous study was conducted in our laboratory using the well characterized Chinese 
Hamster Ovary strain 36 (CHO 36) recombination cell line (Defoort et al., 2006). In this study, exposure to $5 \mathrm{mM}$ and $10 \mathrm{mM} \mathrm{VPA}$ for $24 \mathrm{hrs}$ caused an increase in HR frequency (Figure 1.6). Early exposure to VPA at these concentrations also caused an increase in intracellular ROS but not oxidative DNA damage (Figure 1.7). Therefore, the full mechanism of VPA-initiated HR remains unclear.

\subsection{Inhibition of Histone Deacetylase as a Mechanism of Teratogenesis}

More recently, the ability of VPA to inhibit HDAC has been implicated in VPAinduced teratogenesis. HDACs are a group of enzymes that are responsible for removal of acetyl groups on proteins involved in a number of important cellular processes including proliferation, differentiation and death (Xu et al., 2007). Eighteen HDACs have been identified in humans and are categorized into 4 classes based on yeast homology (Xu et al., 2007). Class I HDACs include HDAC1, 2, 3 and 8 and are found in the nucleus while Class II HDACs including HDAC4, 5, 6, 7, 9, and 10 can be transported between the nucleus and the cytoplasm in response to certain signals (Vavrova et al., 2005). Class III includes a family of sirtuins and Class IV is represented by HDAC11 (Xu et al., 2007). VPA has been shown to inhibit both Class I (HDAC1-3, 8) and Class II (HDAC4, 5, 7) HDACs to regulate the transcription of a number of genes

involved in cell cycle progression, differentiation and cell cycle arrest (Duenas-Gonzalez et al., 2008). The predominant substrates for HDACs in the nucleus are histones. 


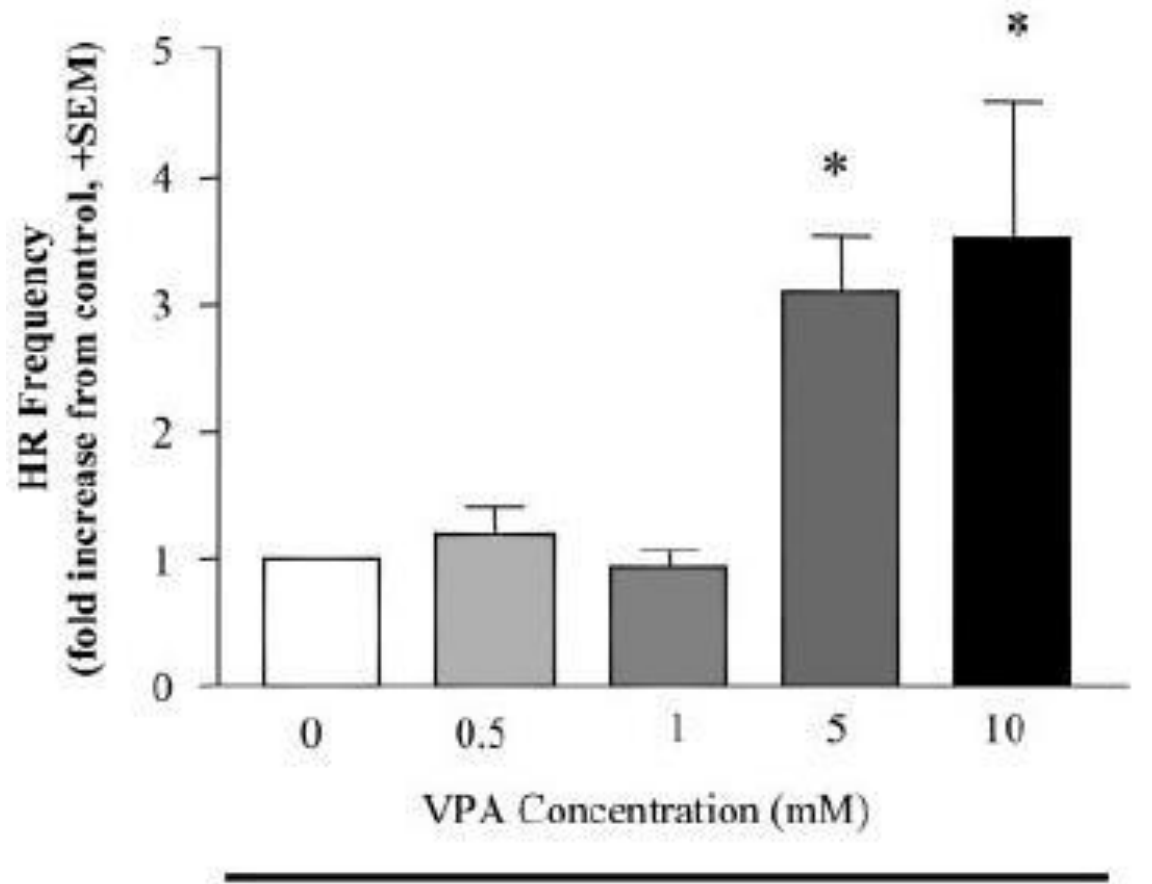

$24 \mathrm{hr}$

Figure 1.6 Valproic acid-induced homologous recombination.

A three-fold increase in HR frequency was observed in CHO 36 cells exposed to $5 \mathrm{mM}$ or $10 \mathrm{mM}$ VPA for $24 \mathrm{hrs}$, which suggest VPA can increase HR. (*denotes significant difference from the control treatment group, p<0.05; From Defoort et al., 2006). 

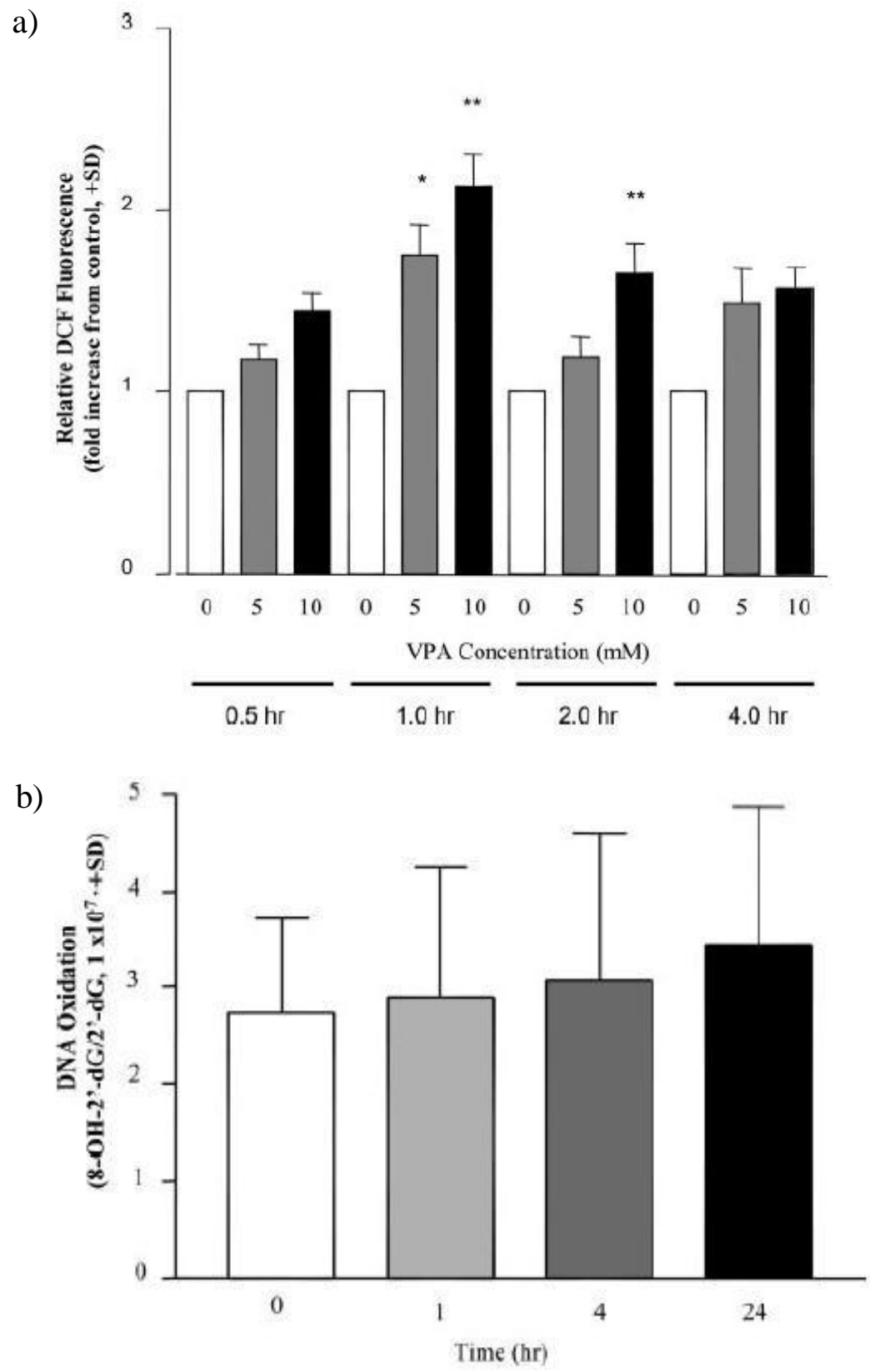

Figure 1.7 Oxidative stress as a mechanism of valproic acid-induced homologous recombination.

a) An increase in intracellular ROS was observed in CHO 36 cells exposed to 5 $\mathrm{mM}$ or $10 \mathrm{mM}$ VPA for 1 and $2 \mathrm{hrs}$, b) however no DNA oxidation was seen during early exposure to VPA (*and **denotes significant difference from the control treatment group; *, $\mathrm{p}<0.01$;**, $\mathrm{p}<0.001$; From Defoort et al., 2006). 
These proteins assemble into histone octamers containing two molecules of each histone $\mathrm{H} 2 \mathrm{~A}, \mathrm{H} 2 \mathrm{~B}, \mathrm{H} 3$ and $\mathrm{H} 4$ in which DNA is wrapped around to form the nucleosome, the basic unit of chromatin (Vavrova et al., 2005). The $\mathrm{N}$ terminal tails of histones are subject to five types of post-translational covalent modifications including acetylation, methylation, phosphorylation, ADP-ribosylation, and ubiquination (Vavrova et al., 2005). Acetylation is the most studied among these modifications and the dynamic acetylation status of histones is determined by histone acetyl-transferases (HAT) and HDACs (Xu et al., 2007). HAT adds acetyl groups to lysine residues on the $\mathrm{N}$-terminal tails of histone $\mathrm{H} 3$ and $\mathrm{H} 4$ while HDAC is responsible for removal of these acetyl groups ( $\mathrm{Xu}$ et al., 2007). Addition of acetyl groups to histone tails weakens the interaction between DNA and histone proteins leading to a relaxed chromatin structure where active transcription can occur (Xu et al., 2007). In contrast, HDAC activity causes deacetylation of histones leading to a highly condensed chromatin structure and inhibition of transcription (Xu et al., 2007, Figure 1.8). Therefore, by inhibiting HDACs, HDAC inhibitors can promote active transcription through chromatin remodeling. Hyperacetylation of histones and relaxation of chromatin can also lead to increased susceptibility of DNA damage. Therefore, preclinical studies have been conducted to determine the synergistic effects of HDAC inhibitors and cytotoxic agents since HDAC inhibitors can improve the access for cytotoxic agents to target DNA/protein complexes (Carraway and Gore, 2007).

One of the first studies that linked inhibition of histone deacetylase by VPA and 


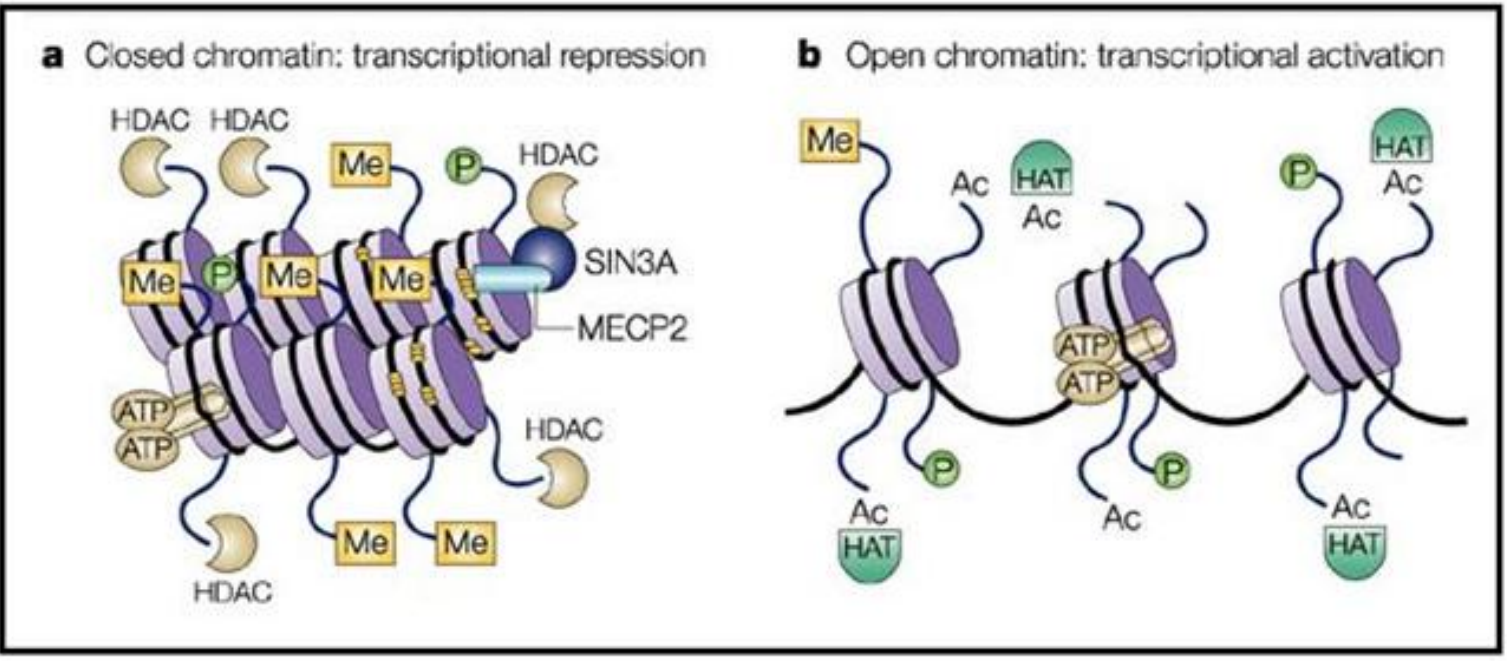

Figure 1.8 Regulation of transcriptional activity through post-translation acetylation of histones.

a) DNA methylation and histone deacetylation leads to a condensed chromatin structure where transcription is repressed whereas b) histone acetylation and demethylation of DNA leads to a relaxed chromatin structure where active transcription can occur. Chromatin structure can also be regulated by phosphorylation of histones and ATPdependent chromatin remodelers. Methyl-binding proteins (MECP2) target methylated DNA and recruit HDACs. Black lines represent DNA while purple cylinders represent histone octamers. Abbrevations: HAT, histone acetyl-transferase; HDAC, histone deacetylase; ME, methyl group; P, phosphoryl group, Ac, acetyl group; MECP2, methylCpG-binding protein, SIN3A, SIN3 homolog A (modified from Johnstone, 2002). 
teratogenesis was conducted by Gurvich et al. (2005) who found VPA and other HDAC inhibitors including trichostatin A (TSA) caused very similar and characteristic developmental defects together with hyperacetylation of histone H4 in Xenopus and zebrafish embryos. However, VPA analogs that have poor HDAC inhibitory activity had little teratogenic effect. Similarly, valpromide, an analog of VPA that does not have any HDAC inhibitory effect, did not induce NTDs in mice (Nau and Loscher, 1986) while in another study, VPA and TSA both induced similar axial skeleton defects and hyperacetylation of histone $\mathrm{H} 4$ at the level of the caudal neural tube and somites in mice embryos (Menegola et al., 2005).

\subsection{Research Rationale, Hypothesis and Objectives}

\subsubsection{Research Rationale}

Antiepileptic agents are often required for women with epilepsy during pregnancy and chronic exposure to these drugs can significantly increase the risk of birth defects two or three times higher than the general population (Pennell, 2007). VPA is a teratogen known to cause both structural and functional congenital malformations in children when taken throughout pregnancy. However, the mechanism behind its teratogenicity remains unclear.

Several studies have demonstrated that exposure to VPA during development leads to oxidative stress. Increased ROS can cause oxidative DNA damage leading to DNA DSBs which can be repaired through HR. The HR system is crucial for 
development, as demonstrated in mice lacking HR proteins, wherein embryonic survival is reduced and mice that do survive have developmental defects (Lim and Hasty, 1996; Tebbs et al., 1997; Ludwig et al., 1997). Although sister chromatids are present for HR repair during development, since cells are dividing rapidly, this repair system is not error free. Genomic rearrangements can occur leading to genome instability. Since proper development requires tight control of the expression of genes, disruption of this process and inappropriate expression of certain genes as a result of erroneous repair may underlie a mechanism of VPA-induced teratogenicity. An increase in HR has been observed after VPA exposure in vitro (Defoort et al., 2006); however the full mechanism of this increase in repair remains unclear.

More recently, the ability of VPA to inhibit HDAC has also been implicated in VPA-induced teratogenesis. Inhibition of HDAC results in hyperactylation of histones, leading to a relaxed chromatin structure where active transcription can occur. In HR repair, over expression of genes involved in HR has been shown to increase HR repair activity (Arnaudeau et al., 1999; Park, 1995; Vispe et al., 1998). In addition, hyperacetylation of histones and relaxation of chromatin can also lead to increased susceptibility to DNA damage.

\subsubsection{Hypothesis}

VPA-initiated HR is mediated by VPA's HDAC inhibitory activity either through altering repair activity or indirectly by causing DNA damage which elicits repair (Figure 1.9). 


\subsubsection{Objectives}

There are three general objectives to this research.

Objective 1: To determine if VPA can cause hyperacetylation of histones in CHO 33 cells.

Objective 2: To determine if VPA can affect the activity of HR repair.

Objective 3: To determine if VPA can increase the susceptibility to DNA DSBs. 


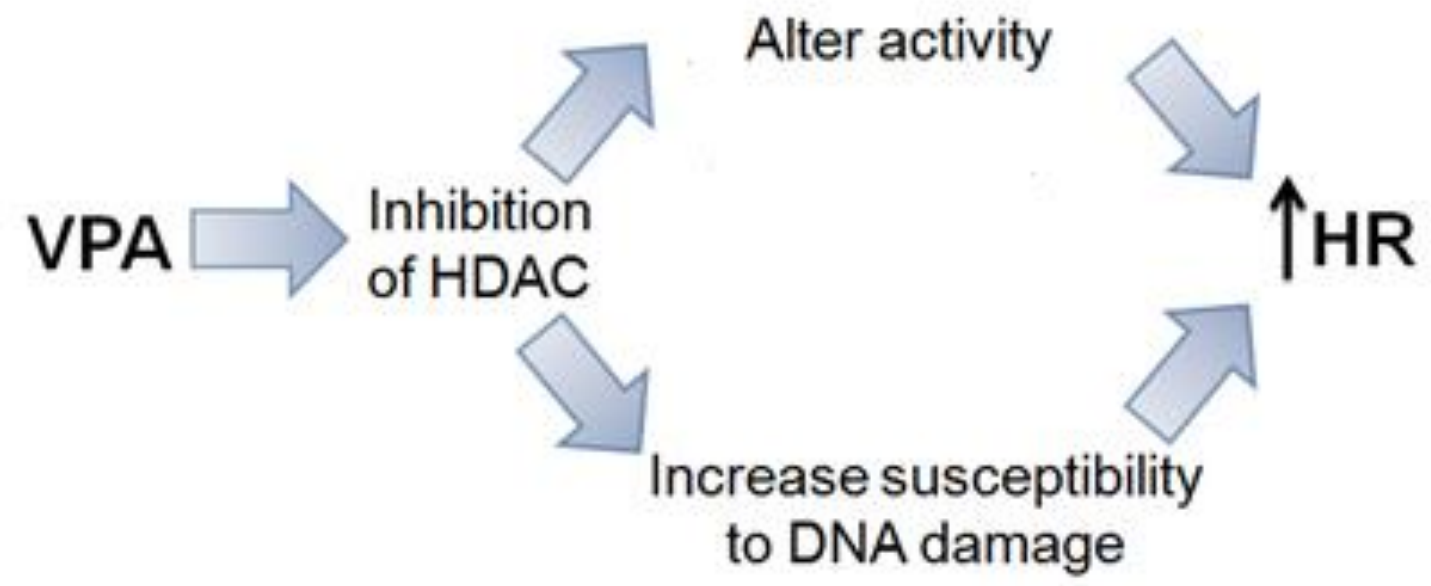

Figure 1.9 Schematic of the hypothesized mechanism of valproic acid-initiated homologous recombination.

Inhibition of histone deacetylation by VPA may increase HR repair through altering repair activity or hyperacetylation of histone and relaxation of chromatin structure may lead to increase susceptibility to DNA damage to initiate HR. 


\section{Chapter 2}

\section{Materials and Methods}

\subsection{Cell Culture}

CHO 33 cells were obtained from J.A. Nickoloff (Department of Molecular Genetics and Microbiology, University of New Mexico, U.S.A.). These cells have a single, stably integrated tandem repeat neomycin (neo) recombination substrate (Taghian and Nickoloff, 1997, Figure 2.1), which confers resistance to the antibiotic Geneticin® (G418; Invitrogen, Carlsbad, CAL) upon HR. The recombination substrate is flanked with EcoRI restriction enzyme cut sites on both ends. The neo gene located on the 5' end of the substrate is inactive due to the insertion of the Saccharomyces cerevisiae mitochondrial endonuclease I-Sce 1 sequence causing a frame shift mutation. Therefore, the intracellular expression of I-Sce 1 will cause a DSB at that specific site within the neo recombination substrate. On the 3 ' end of the substrate, the wildtype neo gene is silent due to the lack of a promoter. This 3' neo serves as the DNA donor for the repair of the I-Sce 1 site of the 5' neo. Therefore this cell line allows for the selection of the occurrence of HR since cells that have undergone HR will be resistant to G418 due to the expression of a functional neo gene. Cells were grown in $15 \mathrm{~cm}$ culture dishes (Corning incorporated, Corning, NY), maintained in $\alpha$-minimum essential medium supplemented with $10 \%$ fetal bovine serum and $1 \%$ penicillin/streptomycin (all from Thermo Scientific 


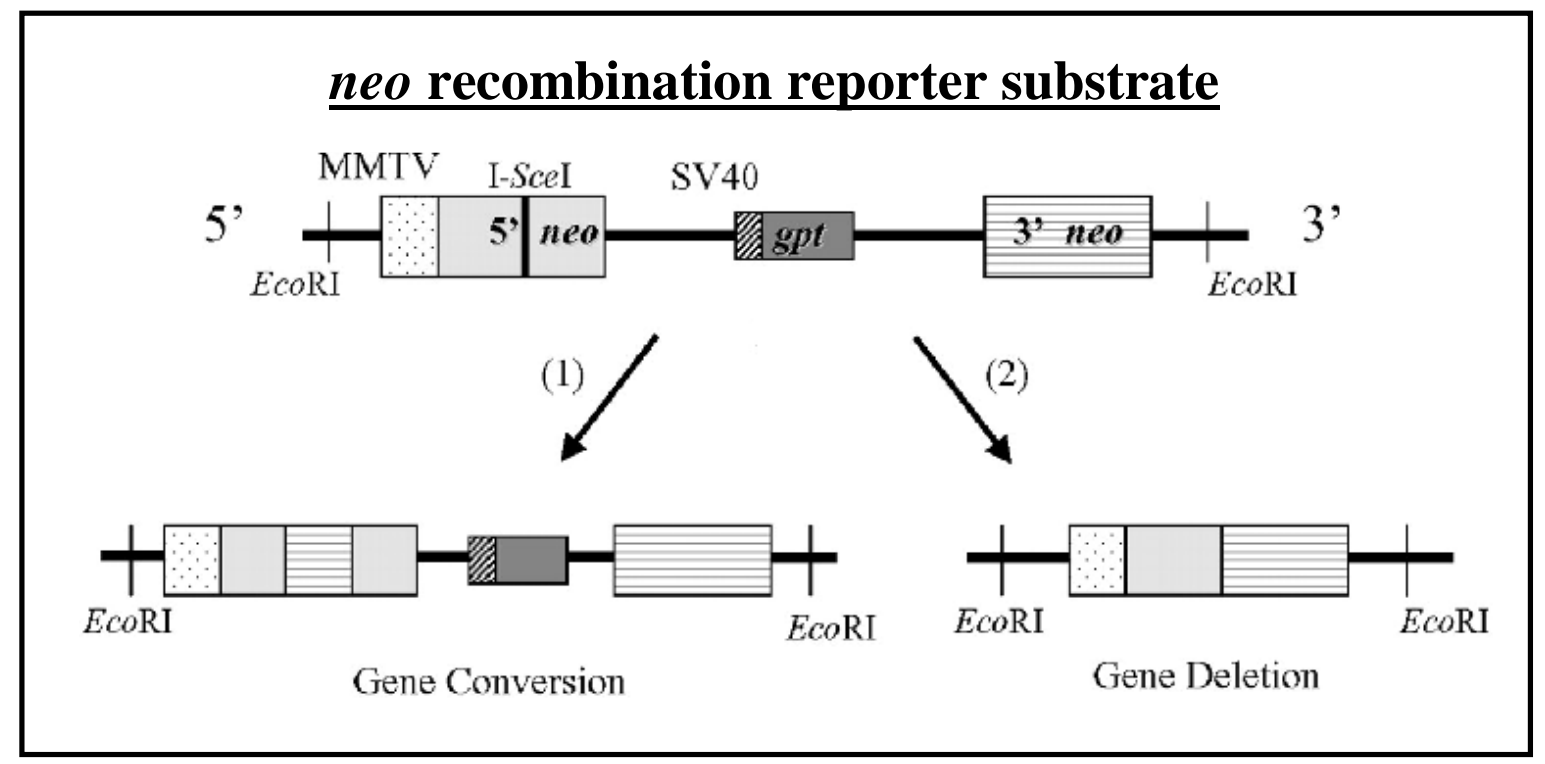

Figure 2.1 Recombination reporter substrate.

CHO 33 cells contain a stably integrated tandem repeat neo recombination reporter plasmid that consists of a dexamethasone inducible 5' mouse mammary tumour virus neo which is inactivated by an I-Sce 1 endonuclease recognition sequence, a central simian virus 40 promoter-driven E.Coli gpt (guanine phosphoribosyl transferase) gene which confers resistance to mycophenolic acid, and a wild-type 3' neo which acts as the DNA donor for the repair of the 5' neo. This 3' neo is inactive because it lacks a promoter. Pathway 1 demonstrates a gene conversion event while pathway 2 exhibits a gene deletion event. 
HyClone, Logan, UT), and incubated at $37^{\circ} \mathrm{C}$ in $5 \% \mathrm{CO}_{2}$.

\subsection{Immunoblot Analysis of Acetylated Histone H3 and H4}

\subsubsection{Treatment and Sample Preparation}

CHO 33 cells were plated in $10 \mathrm{~cm}$ culture dishes at $30 \%$ density. Twenty four hours after plating, cells were treated with $5 \mathrm{mM}$ VPA or control (media) for 10, 16 or 24 hrs. These time points were based on previous studies that demonstrate the ability of VPA to cause hyperacetylation of histones (Chen et al., 2007; Li et al., 2008; NelsonDeGrave et al., 2004). After the exposure period, cells were lysed with phosphate buffer saline (SDS) containing $0.5 \% \mathrm{NP}-40$ and protein concentrations were determined using the BIO-RAD assay by using an aliquot of each sample of (Bio-Rad Laboratories, Hercules, CA). Sodium dodecyl sulfate (SDS) loading dye buffer $(5 \% \quad \beta$ mercaptoethanol, $0.25 \mathrm{M}$ Tris base, $12.5 \mathrm{mM}$ EDTA, $0.01 \%$ bromophenol blue, 35\% glycerol, and 10\% SDS) was added and samples were boiled for 5 minutes.

\subsubsection{SDS-PAGE and Immunoblotting}

Samples were electrophoresed in a $15 \%$ acrylamide gel (Bio-Rad, Hercules, CA) and transferred onto a polyvinylidene membrane (Millipore, Billerica, MA). The membrane was cut in half at the $25 \mathrm{kDa}$ band and probed for either $\beta$-actin (42 kDa), acetylated histone $\mathrm{H} 3(17 \mathrm{kDa})$ or $\mathrm{H} 4(10 \mathrm{kDa})$. For acetylated $\mathrm{H} 3$ and $\mathrm{H} 4$, membranes were blocked with $3 \%$ bovine serum albumin (BSA) for 30 minutes and then incubated overnight with anti-acetyl-histone H3 or H4 (Millipore, Billerica, MA). Membranes were 
then washed and incubated with donkey anti-rabbit horseradish peroxidase-conjugated secondary antibody (Amersham, United Kingdom) for $1 \mathrm{hr}$ and visualized using an enhanced chemiluminescence detection system (Perkin Elmer, MA). For $\beta$-actin, membranes were blocked with $3 \%$ non-fat milk for 30 minutes and then incubated overnight with anti- $\beta$-actin primary antibody (Sigma-Aldrich, St. Louis, MO). Membranes were then washed and incubated with sheep anti-mouse horseradish peroxidase-conjugated secondary antibody (Amersham, UK) for $1 \mathrm{hr}$ and visualized using an enhanced chemiluminescence detection system (Perkin Elmer, MA).

\subsection{Double-Strand Break-Induced Recombination Assay}

CHO 33 cells were plated in treated 6-well tissue culture plates (Corning Incorporated, Corning, NY) at a density of $3 \times 10^{5}$ cells/well. Cells in each well were transiently transfected with $1 \mu \mathrm{g}$ of plasmid cDNA expressing the I-Sce1 restriction enzyme or the control plasmid (pGem, an empty expression vector) 24 hrs after plating using Lipofectamine ${ }^{\mathrm{TM}}$ according to the manufacturers' instructions. Twenty-four hrs after transfection, $5 \times 10^{4}$ cells from each well were transferred to $10 \mathrm{~cm}$ culture dishes containing fresh media. The cells were allowed to adhere for $3 \mathrm{hrs}$ after plating and then exposed to $5 \mathrm{mM}$ VPA (Sigma-Aldrich, St. Louis, MO) or the vehicle control (media). After $24 \mathrm{hrs}$ of drug exposure, the medium was removed and the cells were washed twice with phosphate buffer saline (PBS) and fresh media containing $250 \mu \mathrm{g} / \mathrm{ml}$ of G418 was added. The cells were grown for 2 weeks and then stained with $1 \%$ crystal violet dye 
(Sigma-Aldrich, St. Louis, MO) in ethanol. HR frequency was determined by counting the number of G418-resistant colonies per live cells plated.

Plating efficiency (cell survival) experiments were conducted in a similar manner to the recombination assay except that $\mathrm{CHO} 33$ cells were plated at a density of 300 cells per $10 \mathrm{~cm}$ dish, cells were grown in fresh cell culture media without G418 and the colonies were counted after 1 week.

\subsection{Double-Strand Break-Induced Recombination Assay with Trichostatin A}

For comparative HR studies with Trichostatin A (TSA), the same protocol was used as in the double-strand break-induced recombination assay, except CHO 33 cells were treated with either TSA (10 nM, $50 \mathrm{nM}$ or $100 \mathrm{nM}$; Chen et al., 2007; Leng and Chuang, 2006) or VPA (5 mM) .

\subsection{Immunocytochemical Analysis of DNA DSBs using $\gamma$-H2AX}

CHO 33 cells were plated on microscope cover slips (Thermo Fisher Scientific, Logan, UT) in 24-well tissue culture plates (Corning Incorporated, Corning, NY) at a density of $2.5 \times 10^{4}$ per cover slip. Twenty-four hrs after plating, cells were treated with $5 \mathrm{mM}$ VPA or media for 10,16 or $24 \mathrm{hrs}$. After the exposure period, cells were fixed with $50 \%$ methanol/50\% acetone and cell membranes were permeabilized with $0.2 \%$ Triton-X100 (Sigma-Aldrich, St. Louis, MO) in PBS. Cover slips were then blocked with 5\% BSA/5\% normal goat serum for $1 \mathrm{hr}$ and incubated with anti- $\gamma-\mathrm{H} 2 \mathrm{AX}$ primary 
antibody (Millipore, Billerica, MA) for another hour. After incubation with primary antibody, cover slips were washed and incubated with goat anti-mouse Alexa Fluor 488®-conjugated secondary antibody (Invitrogen, Carlsbad, CAL) for $1 \mathrm{hr}$ and 15 minutes. Cover slips were then incubated with 4',6-diamidino-2-phenylindole (DAPI) for 3 minutes to stain the nucleus and then cover slips were washed and mounted to microscope slides. Images were taken using a Leica DM 4000 B microscope equipped with a 80x oil immersion objective and a Leica DFC 350X camera. Images were analyzed using the Image-Pro Plus software version 5.0.

\subsection{Double-Strand Break-Induced Recombination Assay with Pretreatment with PEG-Catalase}

For HR studies using polyethylene glycol (PEG)-catalase, a similar protocol was used as in the double-strand break-induced recombination assay, except $400 \mathrm{U} / \mathrm{ml}$ of PEG-catalase was added immediately after cell plating, and the cells were incubated for $24 \mathrm{hrs}$ before being exposed to $5 \mathrm{mM}$ VPA for $24 \mathrm{hrs}$ (Defoort et al., 2006).Treatment with PEG-catalase and media alone was used as controls.

\subsection{ROS Studies}

CHO 33 cells were plated in 6-well tissue culture plates (Corning Incorporated, Corning, NY) at a density of $3 \times 10^{5}$ cells/well. Twenty-four hrs after plating, cells were treated with $5 \mathrm{mM}$ VPA or media for 10,16 or $24 \mathrm{hrs}$. Two hrs prior to the time point of 
interest, cells were incubated with $10 \mu \mathrm{M}$ of the oxidation-sensitive fluorescent probe, 5(and-6)-chloromethyl-2-7-dichlorodihydrofluorescein diacetate $\quad$ (CM- $\mathrm{H}_{2}$ DCFDA; Invitrogen, Carlsbad, CA). Intracellular esterase activity will remove the diacetate group leaving the probe in a charged form which is retained in cells. The interaction of CM$\mathrm{H}_{2} \mathrm{DCF}$ with intracellular ROS results in dichlorofluorescein derivatives, which are highly fluorescent (Camargo et al., 2009). Therefore, dichlorofluorescein fluorescence was measured by flow cytometry as an indication of the relative amount of intracellular ROS. Prior to flow cytometry, cells were washed three times with PBS and re-suspended in $5 \mu \mathrm{g} / \mathrm{ml}$ of propidium iodine in PBS to exclude apoptotic and necrotic cells from the experiment.

\subsection{DNA Oxidation}

\subsubsection{Treatment and Isolation of Deoxynucleosides}

CHO 33 cells were plated in 6-well tissue culture plates (Corning Incorporated, Corning, NY) at a density of $3 \times 10^{5}$ cells/well. Twenty-four hrs after plating, cells were treated with $5 \mathrm{mM}$ VPA or media for 10, 16 or $24 \mathrm{hrs}$. After the exposure period, DNA was isolated using the Qiagen DNeasyTM Tissue Kit (Qiagen Inc., Missisauga, ON) and DNA samples were then processed to individual nucleosides using the method described by Huang et al. 2001, except nuclease S1 (10 units/ $\mu 1)$ was used rather than nuclease P1 (1 unit/ $/$ l) and the digest was filtered through a Millipore Ultra-free MC 10,000 nominal molecular weight limit filter unit (Millipore, Billerica, MA). 


\subsubsection{High Pressure Liquid Chromatography with Electrochemical Detection}

8-OH-2'-dG (8-hydroxy-2'-deoxyguanosine), 2'-dG (2'-deoxyguanosine), 5-OH-

C (5-hydroxydeoxycytosine) were separated and quantified using high pressure liquid chromatography with electrochemical detection using a YMCbasic 150 x 4.6 mm column (YMC Inc, Milford, MA) with a $0.1 \%$ methanol/99\% 50mM phosphate buffer (pH 5.5) mobile phase at a flow rate of $1.0 \mathrm{ml} / \mathrm{min}$ (Bolin, C et al., 1995). The separated nucleosides were detected using a CoulArray Electrochemical Detector (ESA Inc, Chelmsford, MA). The amount of each nucleoside was determined by extrapolation from a standard curve which was carried out prior to running the samples for each trial.

\subsection{Statistical Analysis}

Statistical analysis was performed using GraphPad Prism 4 software. Transfection and treatment groups were compared using a two-way analysis of variance (ANOVA) in the recombination assay. Subsequent t-tests were used to compare HR frequencies between treatment groups for each type of transfected cells. For the recombination assay with TSA and pretreatment of PEG-catalase, a one-way ANOVA was used to compare among the different treatment groups. A Newman-Keuls multiple comparison test was used to compare the HR frequency among all treatment groups for post-hoc analysis. For $\gamma$-H2AX, ROS, DNA oxidation studies, t-tests were used to compare the treatment groups for the different time points. Statistical significance was designated if $p<0.05$. 


\section{Chapter 3}

\section{Results}

\subsection{Immunoblot Analysis of Acetylated Histone $\mathrm{H3}$ and $\mathrm{H} 4$}

To determine if HDAC inhibition plays a role in VPA-initiated HR, the ability of VPA to cause hyperacetylation of histone was assessed. The levels of acetylated histone $\mathrm{H} 3$ and $\mathrm{H} 4$ were analyzed after $\mathrm{CHO} 33$ cells were exposed to $5 \mathrm{mM}$ VPA for 10,16 or 24 hrs. An increase in the acetylation of these proteins levels can be seen at all time points in the VPA treated group, with the greatest increase observed at the $16 \mathrm{hr}$ time point (Figure 3.1).

\subsection{Valproic Acid-Induced Cell Death}

Cell survival experiments were carried out to determine the cytotoxic effects of VPA and the transfection process in CHO 33 cells. For both types of transfection (pGem and I-Sce1), exposure to 5mM VPA did not cause a significant change in cell survival compare to the media after $24 \mathrm{hrs}$ of exposure (Figure 3.2). 


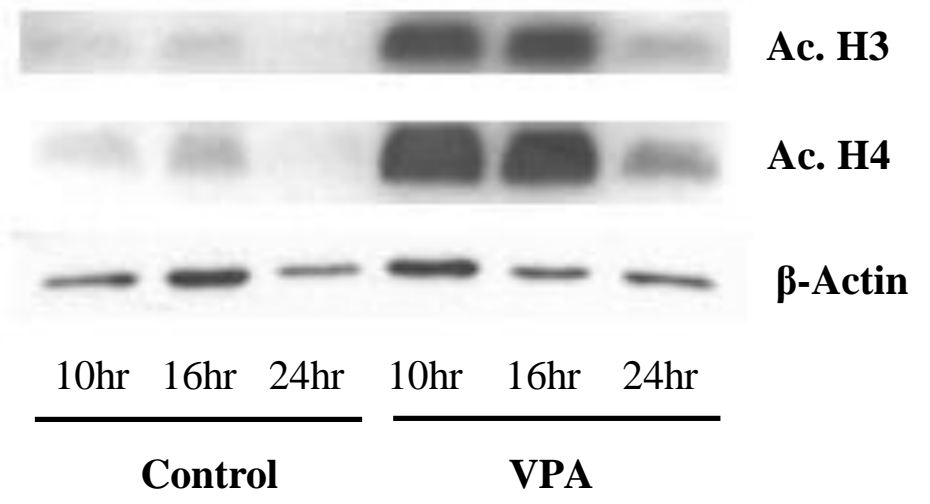

Figure 3.1 Valproic acid-induced hyperacetylation of histone $\mathbf{H 3}$ and H4. Representative immunoblots of acetylated histone $\mathrm{H} 3$ and $\mathrm{H} 4$ of $\mathrm{CHO} 33$ cells exposed to $5 \mathrm{mM}$ VPA for 10,16 or $24 \mathrm{hrs}$. 


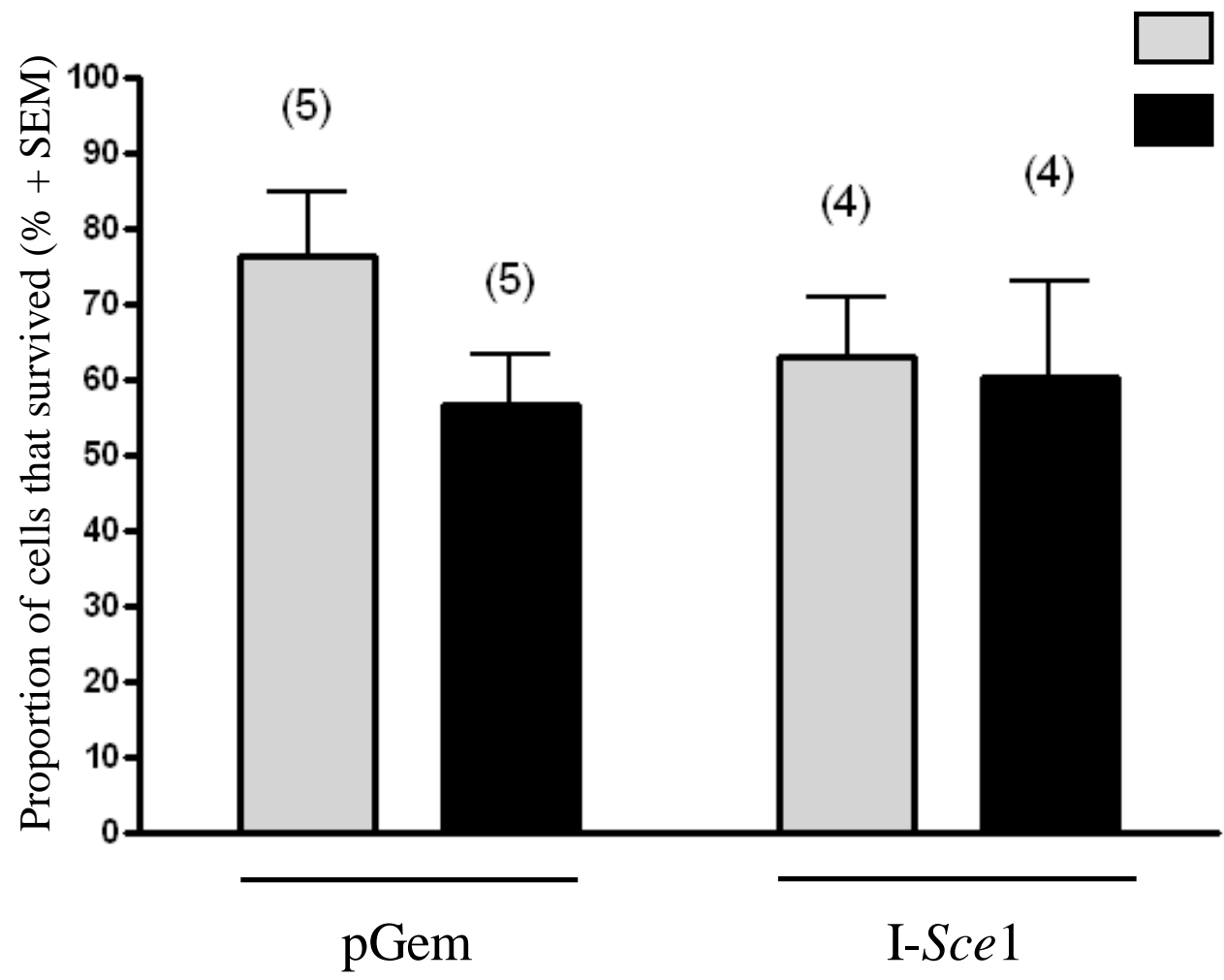

Figure 3.2 Valproic acid and transfection-induced cell death.

Cell survival in I-Sce 1 and pGem transfected CHO 33 cells exposed to $5 \mathrm{mM}$ VPA or control (media) for $24 \mathrm{hrs}$. Cell survival was determined by calculating the number of colonies formed after 1 week divided by the number of cells plated in fresh media without G418. $(\mathrm{p}<0.05)$ 


\subsection{Valproic Acid-Induced Homologous Recombination}

In the DSB-induced recombination assay, exposure to $5 \mathrm{mM}$ VPA for $24 \mathrm{hrs}$ caused a statistically significant increase in HR frequency in both pGem $(\mathrm{p}<0.001)$ and ISce1 $(\mathrm{p}<0.05)$ transfected cells (Figure 3.3). To determine if VPA could affect repair activity, we compared the difference in HR frequency between the VPA and control treatment group of CHO 33 cells transfected with either the pGem or I-Sce1 plasmid. No significant increase was observed in the change in HR frequency due to VPA in the ISce1 group which has a DNA DSB induced compared to the pGem group (Figure 3.4). These results suggest that VPA does not affect repair activity but rather may cause indirect DNA damage which initiates HR repair.

\subsection{Comparative study of Trichostatin A and Valproic Acid Initiated Homologous Recombination}

To determine if VPA-induced HDAC inhibition plays a role in VPA-initiated HR, a comparative study was conducted where CHO 33 cells were treated with TSA, a known HDAC inhibitor and similar to VPA, TSA also inhibits class I and class II HDACs. CHO 33 cells were treated with $10 \mathrm{nM}, 50 \mathrm{nM}$, or $100 \mathrm{nM}$ of TSA and cell survival experiments were carried out to determine the cytotoxic effects of TSA compared to VPA. No significant change in cell survival was observed at all concentrations of TSA compared to VPA for both types of transfected cells (Figure 3.5). In the DSB-induced recombination assay, no significant difference in HR frequency was observed in the TSA 


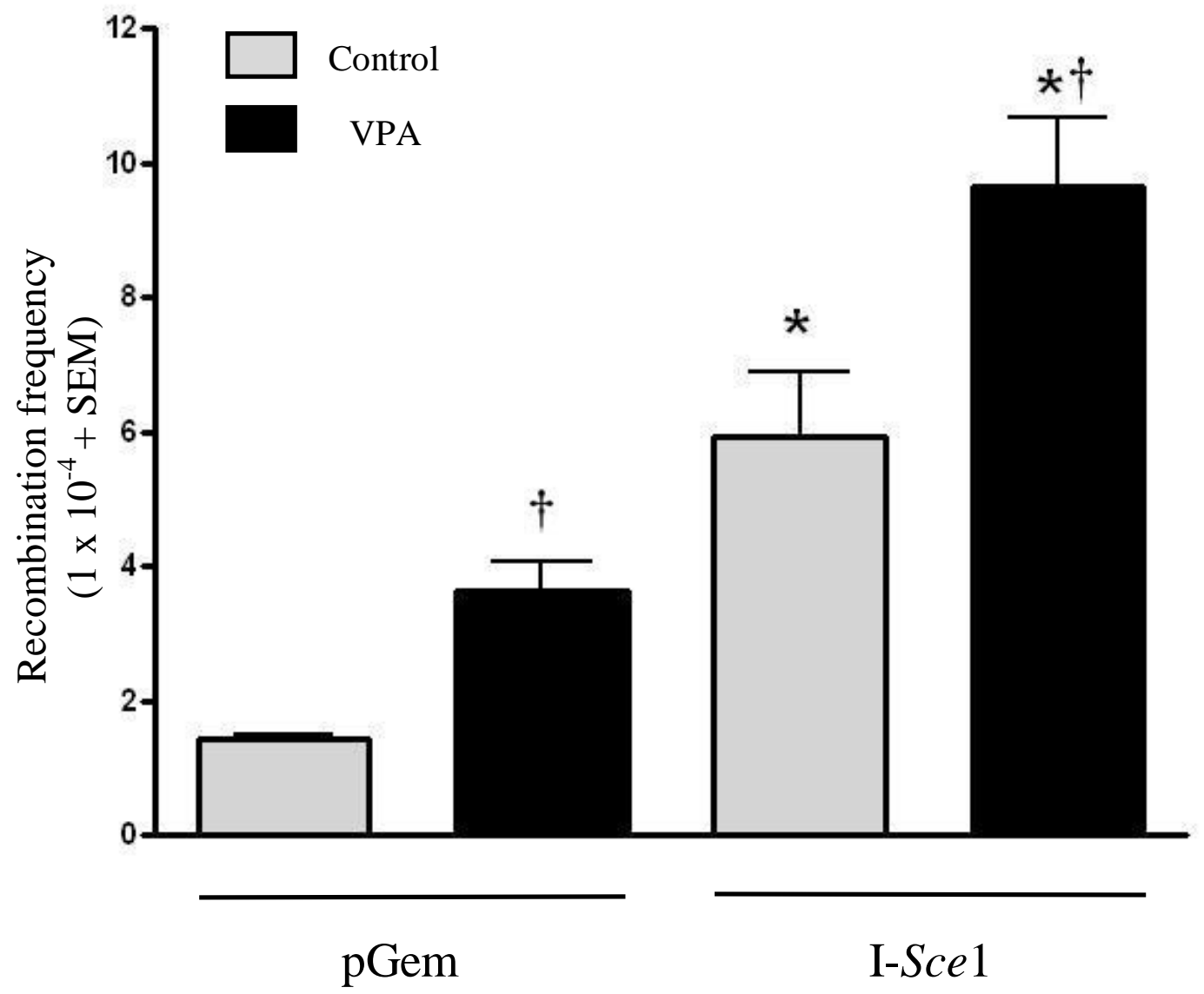

Figure 3.3 Valproic acid-induced homologous recombination.

The frequency of $\mathrm{HR}$ in I-Sce 1 and pGem transfected CHO 33 cells exposed to $5 \mathrm{mM}$ VPA or control (media) for $24 \mathrm{hrs}$ was determined by counting the number of G418resistant colonies formed after 2 weeks divided by the number of live cells. (*denotes significant difference from cells transfected with the control plasmid (pGem). $\dagger$ denotes a significant difference from cells treated with the medium *, $\dagger p<0.05 ; n=5)$. 


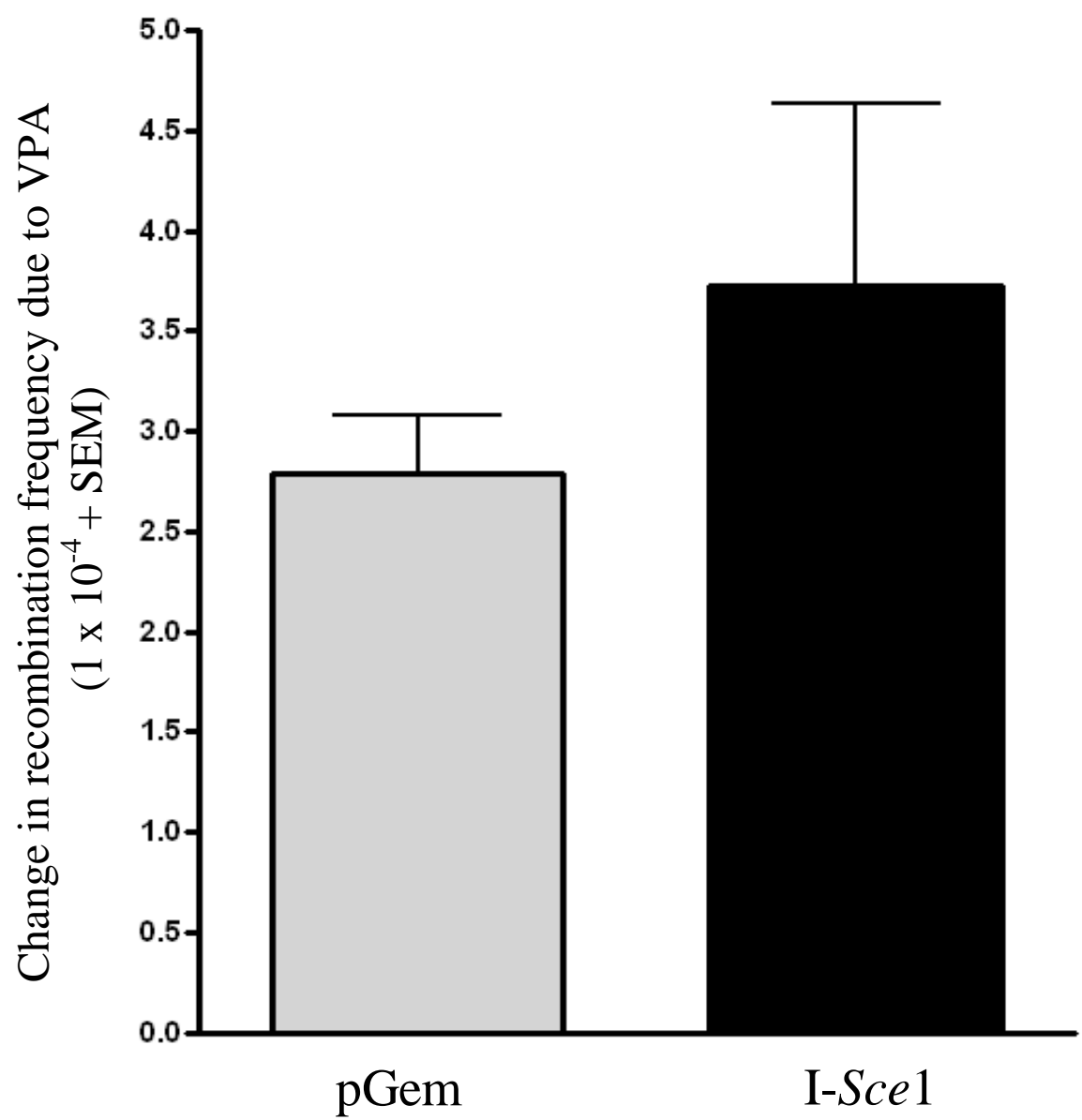

Figure 3.4 Valproic acid does not affect homologous recombination activity.

Comparison of the difference in the frequency of HR between VPA and media treatment in pGem and I-Sce 1 transfected cells. $(\mathrm{p}<0.05)$ 
(a)

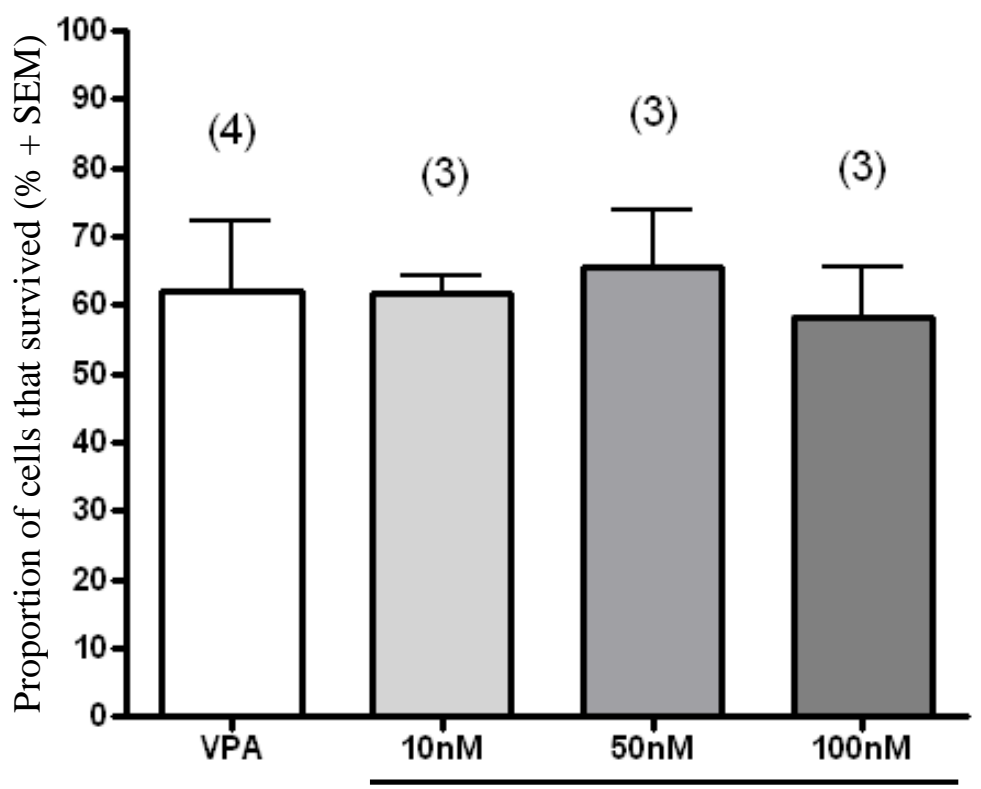

(b)

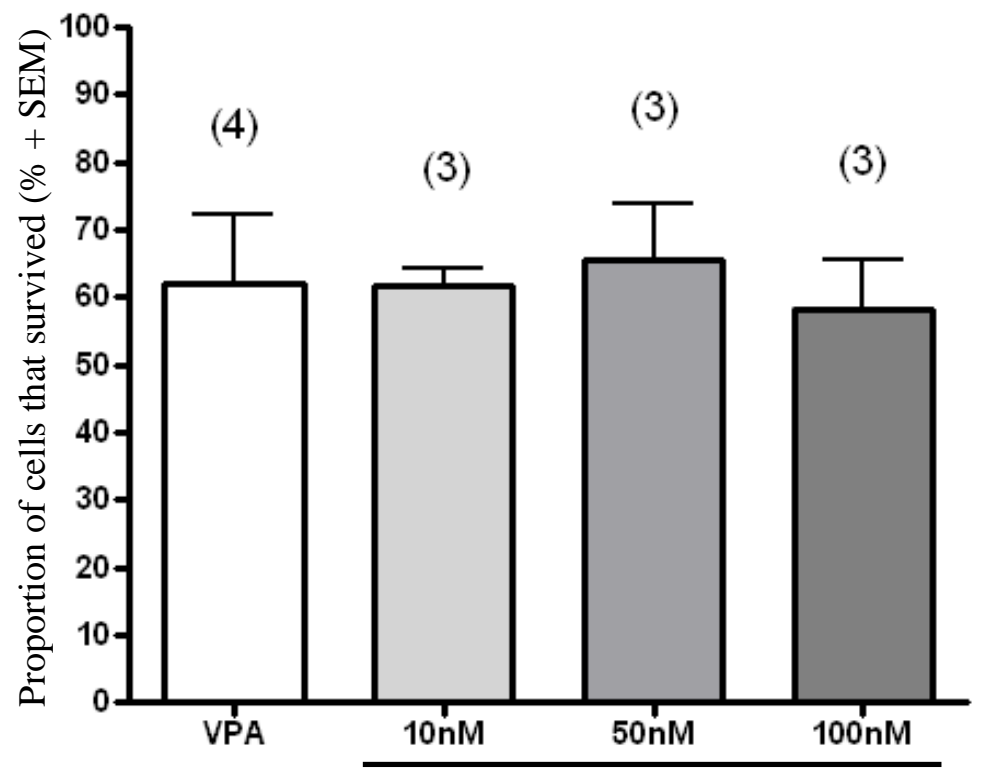

Trichostatin A

Figure 3.5 Valproic acid and trichostatin A-induced cell death.

Cell survival in a) pGem and b) I-Sce 1 transfected CHO 33 cells exposed to $5 \mathrm{mM}$ VPA or TSA (10 nM, $50 \mathrm{nM}$, or $100 \mathrm{nM}$ ) for $24 \mathrm{hrs}$. Cell survival was determined by calculating the number of colonies formed after 1 week divided by the number of cells plated in fresh media without G418. $(\mathrm{p}<0.05)$ 
treated groups compared to the VPA treatment for both types of transfected cells (Figure 3.6). Although a statistically significant increase in HR frequency was seen in the $100 \mathrm{nM}$ TSA treatment group compared to the $10 \mathrm{nM}$ TSA treatment group in the pGem transfected cells (Figure 3.6a). Similar HR frequencies between VPA and TSA suggest inhibition of HDAC by VPA plays a role in VPA-initiated HR.

\subsection{Immunocytochemical Analysis of $\gamma$-H2AX}

The formation of gamma-H2AX $(\boldsymbol{\gamma}-\mathrm{H} 2 \mathrm{AX})$ was assessed to determine if VPA can cause DNA DSBs. H2AX is one of the earliest substrates to be phosphorylated in the presence of a DNA DSB and this specific type of DNA damage would initiate HR repair. Hyperacetylation of histones leads to a relaxed chromatin structure where DNA is susceptible to damage; therefore the formation of $\gamma-\mathrm{H} 2 \mathrm{AX}$ was determined at 10,16 or $24 \mathrm{hrs}$ after exposure to $5 \mathrm{mM}$ VPA. Similar to the levels of acetylated histones, a statistically significant increase in the number of $\boldsymbol{\gamma}-\mathrm{H} 2 \mathrm{AX}$ foci was seen at all time points in the VPA treated groups, with the greatest increase occurring at the $16 \mathrm{hr}$ time point $(\mathrm{p}<$ 0.0001; Figure 3.7). These results demonstrate that VPA can induce DNA DSBs within $24 \mathrm{hrs}$ where an increase in HR was also observed. 


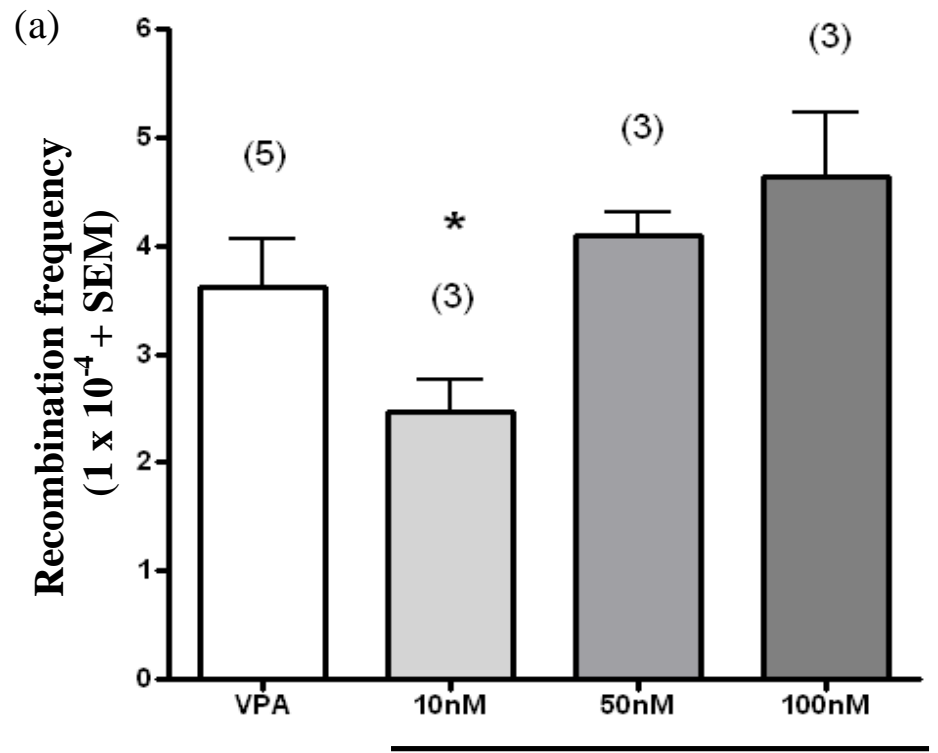

Trichostatin A

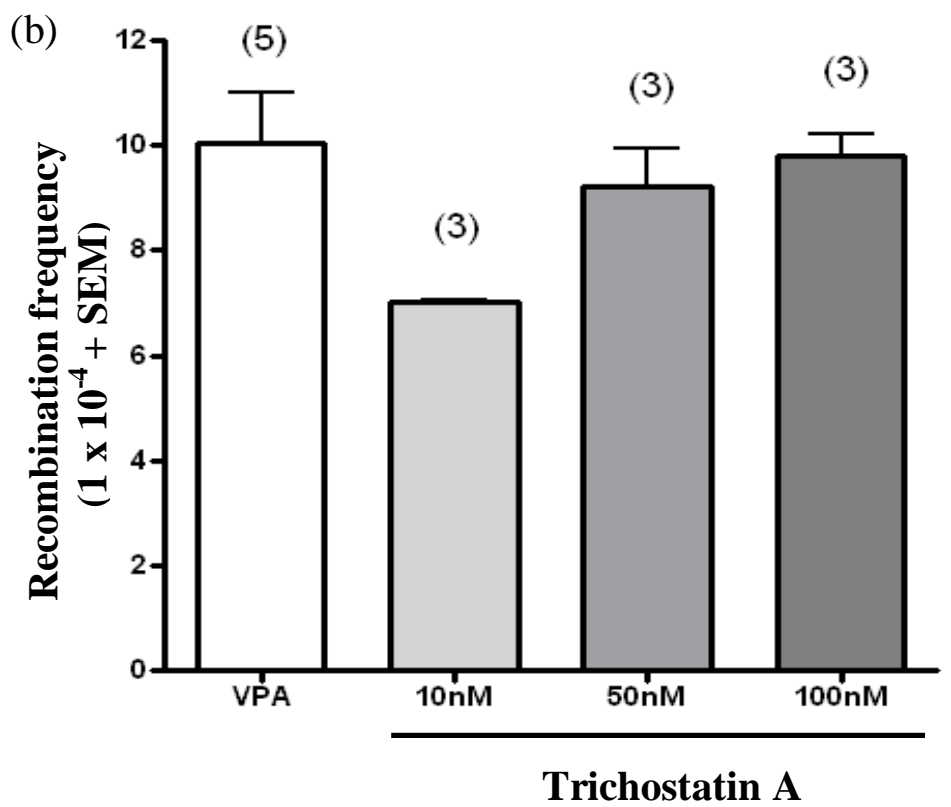

Figure 3.6 Valproic acid and trichostatin A-induced homologous recombination. $\mathrm{HR}$ frequency in a) pGem and b) I-Sce 1 transfected $\mathrm{CHO} 33$ cells exposed to $5 \mathrm{mM}$ VPA or TSA $(10 \mathrm{nM}, 50 \mathrm{nM}$, or $100 \mathrm{nM})$ for $24 \mathrm{hrs}$. HR frequency was determined by counting the number of G418-resistant colonies formed after 2 weeks divided by the number of live cells. (* denotes significant difference from the $100 \mathrm{nM}$ TSA treatment group; $* \mathrm{p}<0.05$ ) 
(a)
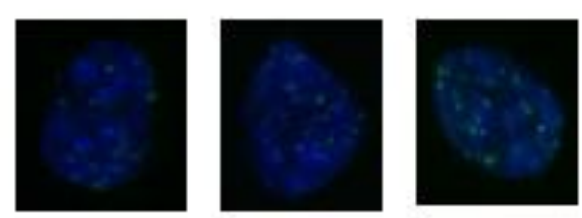

\section{Control}
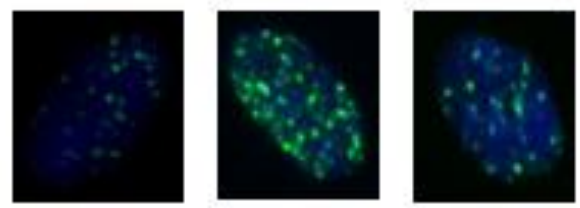

VPA

$10 \mathrm{hr}$

$16 \mathrm{hr}$

24hr

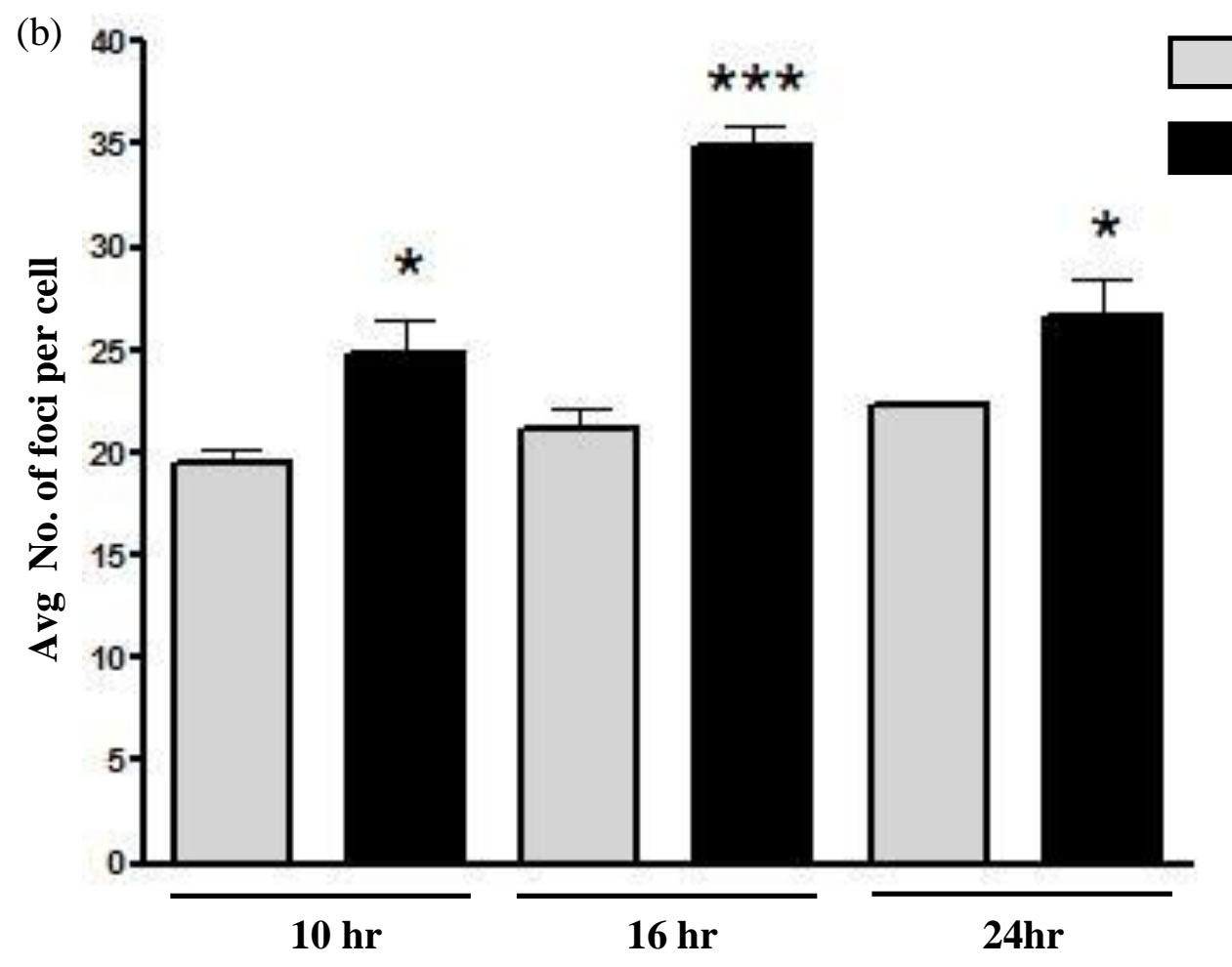

Figure 3.7 Valproic acid-induced DNA double strand breaks.

(a) Representative images of immunocytochemistry staining for $\gamma$-H2AX foci (green) in CHO 33 cells exposed to $5 \mathrm{mM}$ VPA for 10, 16 or $24 \mathrm{hr}$. Nuclei were counterstained with DAPI (blue). (b) Average number of foci formed for each time point. The average number of foci was determined by counting 15 nuclei per replicate in each trial for each time point. Three replicates were included in each trial (* and $* * *$ denotes significant difference from the control treatment group; $* \mathrm{p}<0.05, * * * \mathrm{p}<0.0001 ; \mathrm{n}=4)$. 


\subsection{The Effects of PEG-Catalase Pretreatment on Valproic Acid-Initiated Homologous Recombination}

The DSB-induced recombination assay was carried out to determine if oxidative stress plays a role in mediating DNA DSBs which would induce HR. CHO 33 cells were pretreated with 400 units/ml PEG-catalase (Defoort et al., 2006), an antioxidant, 24 hrs prior to $5 \mathrm{mM}$ VPA treatment and HR frequency was assessed after 2 weeks. Cell survival among the different treatment groups did not differ between both types of transfected cells (Figure 3.8). In the DSB-induced recombination assay, a statistically significant decrease in HR frequency was observed in $\mathrm{CHO} 33$ cells that were pretreated with 400 units/ml of PEG-catalase prior to $5 \mathrm{mM}$ VPA treatment compare to VPA treatment alone $(\mathrm{p}<0.05)$ for both types of transfected cells (Figure 3.9). The protective effect of PEG-catalase against VPA-induced HR suggests ROS may also play a role in VPA-initiated HR.

\subsection{Valproic Acid-Induced ROS Formation}

To verify that VPA exposure generates ROS, intracellular ROS were measured in CHO 33 cells after exposure to $5 \mathrm{mM}$ VPA for 10,16 or $24 \mathrm{hrs}$. At these time points, VPA induces DNA DSBs as seen in our experiments and excess ROS production may

cause oxidative DNA damage leading to DNA DSBs. Intracellular ROS were measured using the ROS sensitive dye, CM- $\mathrm{H}_{2}$ DCFDA. An increase in fluorescence, an 
(a)

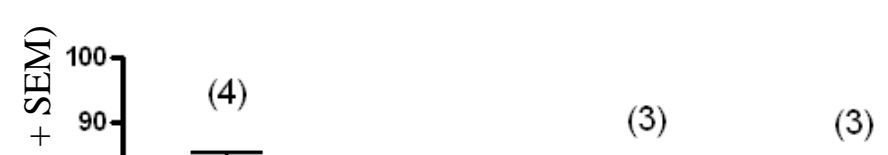

(b)

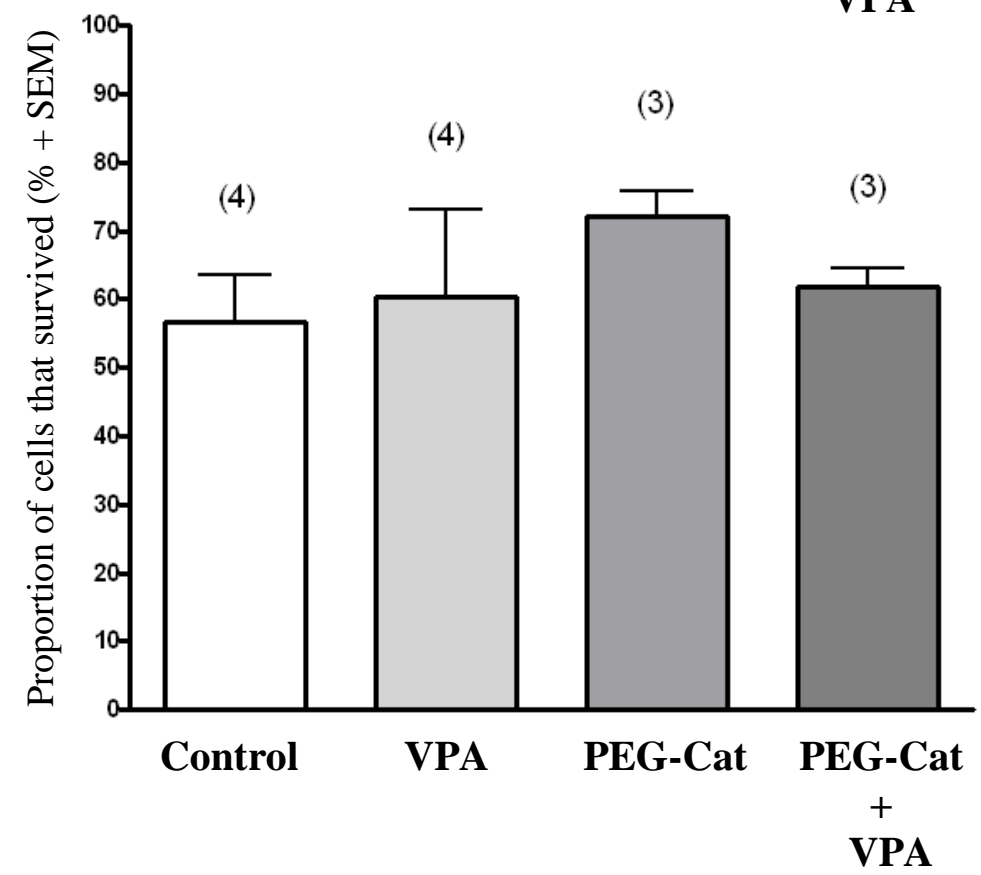

Figure 3.8 Valproic acid and polyethylene glycol-catalase induced cell death.

Cell survival in a) pGem or b) I-Sce 1 transfected CHO 33 cells exposed to $400 \mathrm{units} / \mathrm{ml}$ PEG-catalase and/or $5 \mathrm{mM}$ VPA for $24 \mathrm{hrs}$. Cell survival was determined by calculating the number of colonies formed after 1 week, divided by the number of cells plated in fresh media without G418. $(\mathrm{p}<0.05)$ 
(a)

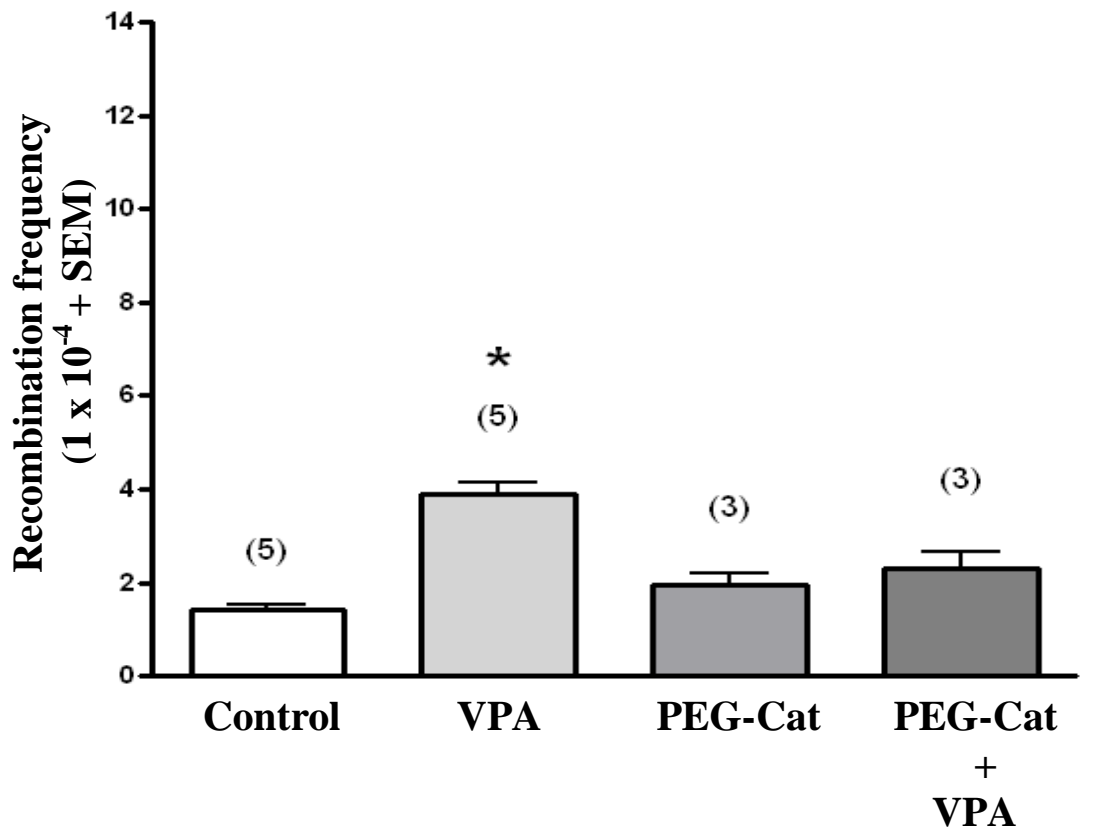

(b)

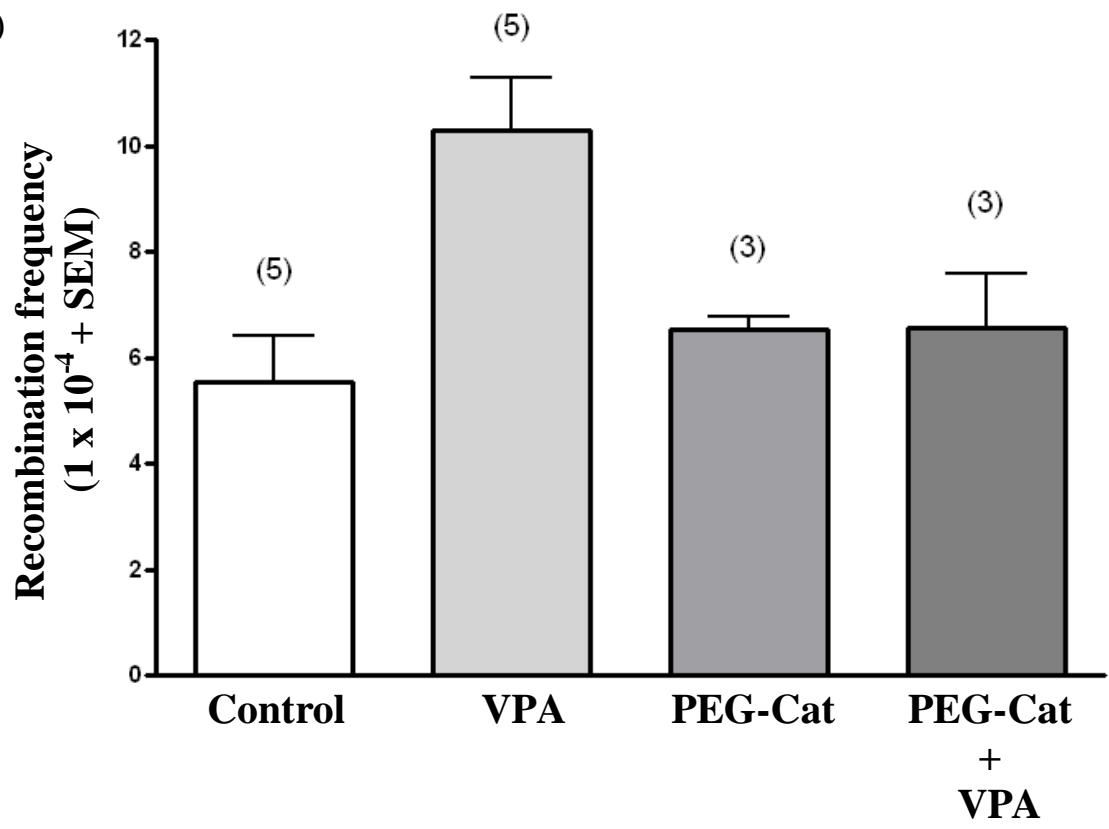

Figure 3.9 Polyethylene glycol -catalase protection against Valproic acid-induced homologous recombination.

The frequency of HR of (a) pGem or (b) I-Sce 1 transfected CHO 33 cells exposed to 400 units/ml PEG-catalase for $24 \mathrm{hrs}$ followed by $5 \mathrm{mM}$ VPA for $24 \mathrm{hrs}$. HR

frequencies were determined by counting the number of G418-resistant colonies formed after 2 weeks divided by the number of live cells. (* denotes significant difference from all other treatment groups; $\mathrm{p}<0.05$ ). 
indicator of ROS formation, was seen at all time points in the VPA treatment group compared to the control group (10 hr: $\mathrm{p}<0.05,16$ and $24 \mathrm{hr}$ : $\mathrm{p}<0.001$, Figure 3.10).

\subsection{Oxidative DNA Damage as a Result of Valproic Acid-Induced ROS}

To determine if VPA-induced ROS caused oxidative DNA damage, CHO 33 cells were exposed to $5 \mathrm{mM}$ VPA for 10,16 or $24 \mathrm{hrs}$ and the ratio of $8-\mathrm{OH}-2^{\prime}-\mathrm{dG} / 2^{\prime}-\mathrm{dG}$ and 5-OH-C/2'-dG was measured as an indicator of oxidative DNA damage. For both types of nucleosides, no significant difference was seen at all time points in the VPA treatment groups compared to the control groups (Figure 3.11). 


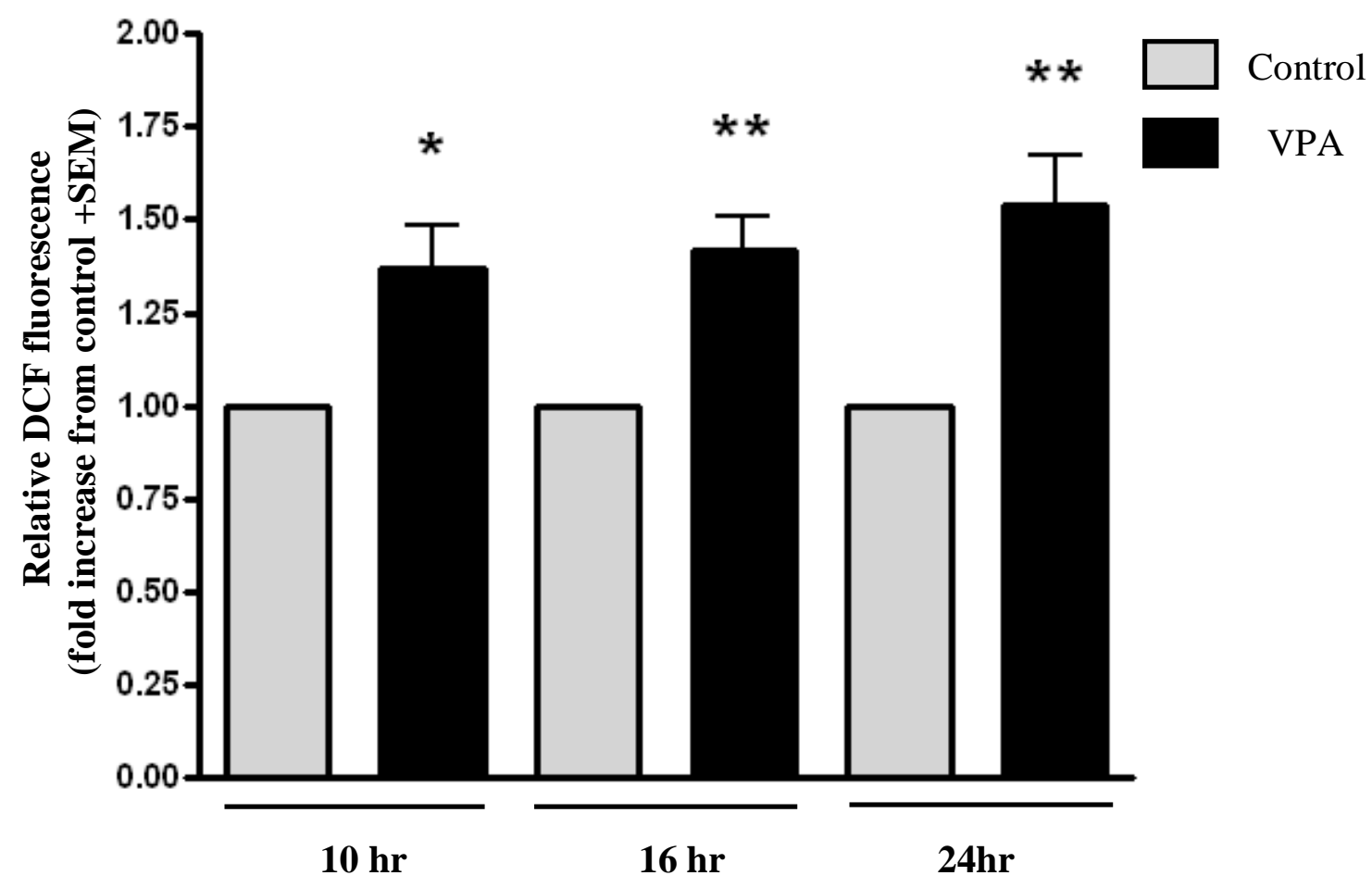

Figure 3.10 Valproic acid-induced reactive oxygen species formation. The relative increase in DCF fluorescence as an indicator of ROS formation in CHO 33 cells exposed to $5 \mathrm{mM}$ VPA or control (media) for 10,16 or 24 hrs. (* and ** denotes significant difference from the control treatment group; $* \mathrm{p}<0.05, * * \mathrm{p}<0.001 ; \mathrm{n}=6$ ). 
(a)

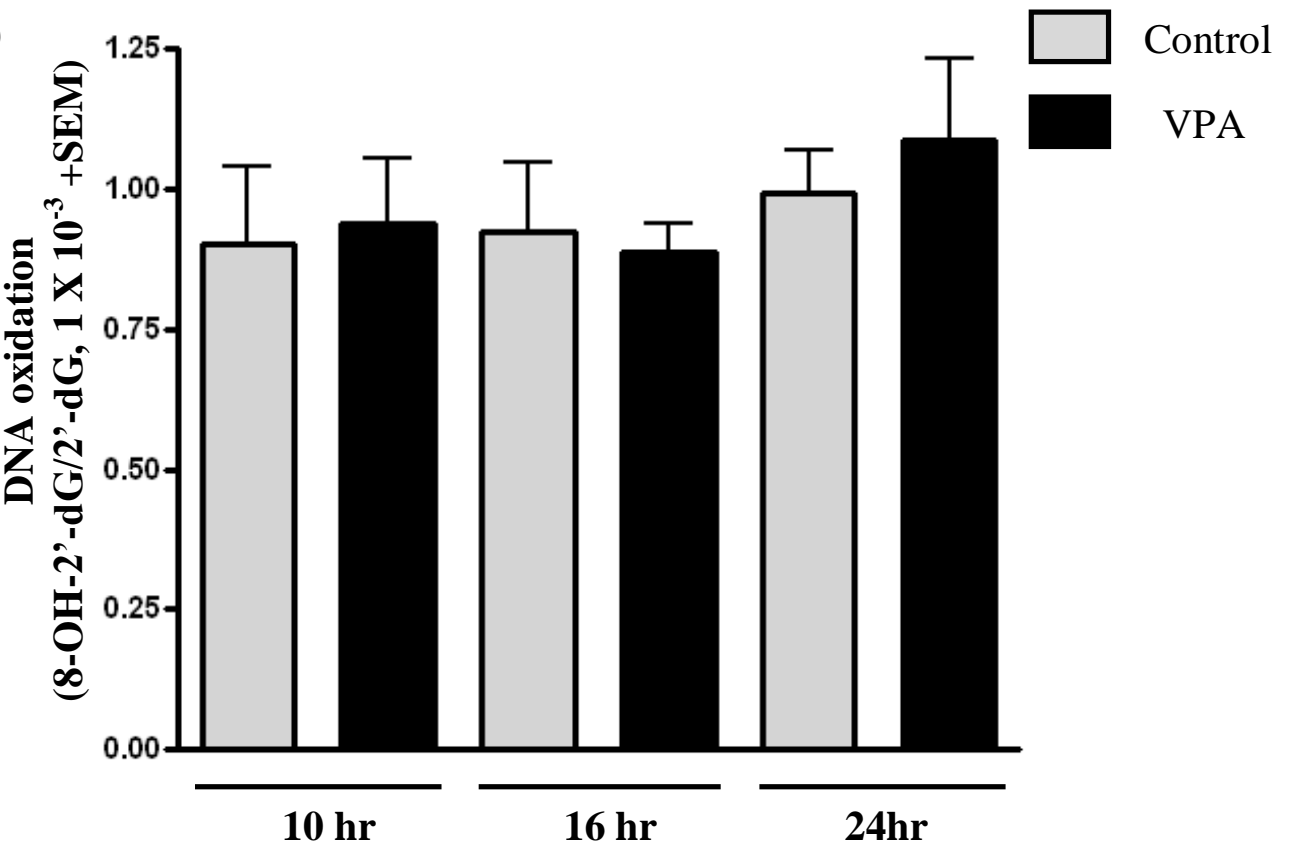

(b)

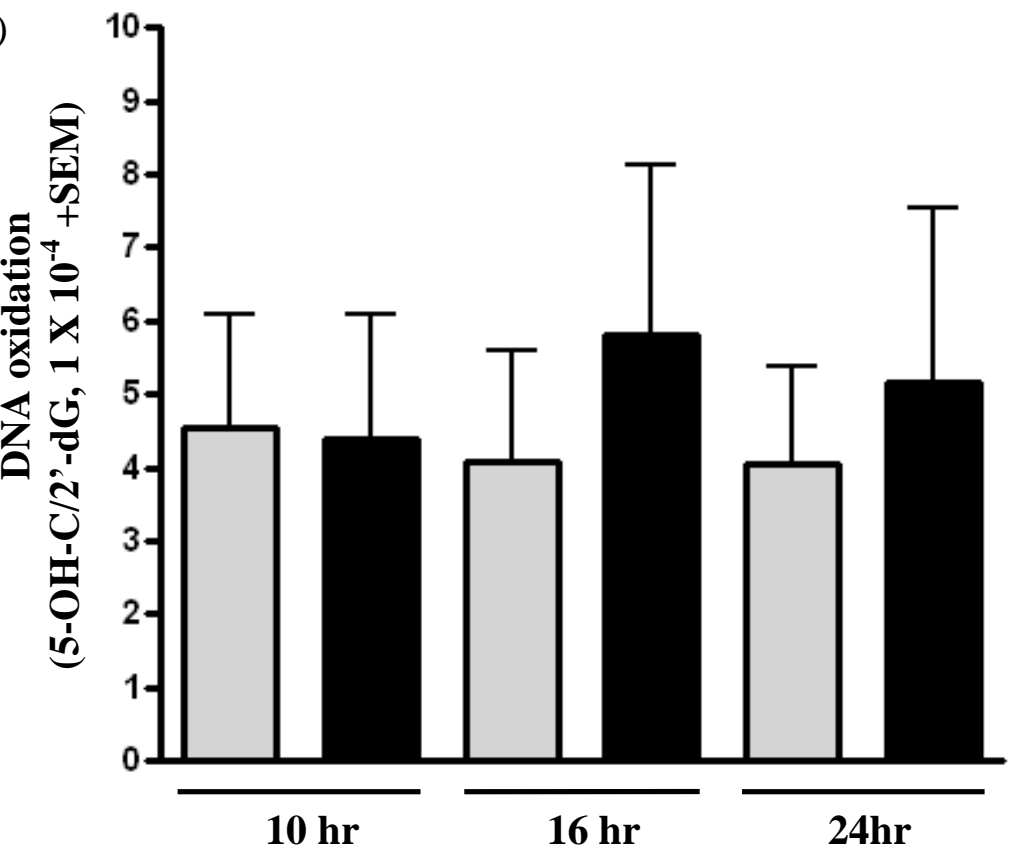

Figure 3.11 Valproic acid-induced DNA oxidative damage.

The ratio of oxidized DNA to the undamaged form of the base in CHO 33 cells following exposure to $5 \mathrm{mM}$ VPA for 10, 16 or 24 hrs. a) $8-\mathrm{OH}-\mathrm{dG}$; $\mathrm{n}=4$, b) 5-OH-C; $\mathrm{n}=4$. $(\mathrm{p}<0.05)$ 


\section{Chapter 4}

\section{Discussion}

\subsection{General Discussion}

VPA is a first line antiepileptic agent used to treat a variety of seizure disorders (Pinkston and Walker, 1997). In addition to its anticonvulsant effects, VPA is also used for the treatment of bipolar disorders, migraine prophylaxis, and neuropathic pain. Current clinical research has been focused on evaluating its anticancer effects (Russell, 2007; Vavrova et al., 2005). However, despite its wide range of therapeutic effects, VPA is a teratogen known to increase the rate of structural and functional birth defects when taken during pregnancy (Eriksson et al., 2005; Kini, 2006). Oxidative stress has been implicated as a potential mechanism of VPA-induced teratogenesis (Baran et al., 2005; Na et al., 2003) and oxidative DNA damage as a result of ROS can lead to DNA DSBs, which can be repair by HR (Kohen and Nyska, 2002). Although a template is used for repair, HR is not an error free process and erroneous repair can lead to gene rearrangements and genomic instability. Since proper development is a tightly regulated process, genomic instability, as a result of erroneous repair, may underlie a mechanism of VPA-induced teratogenicity. A previous study in our laboratory demonstrated the ability of VPA to increase HR; however the full mechanism of this increase in repair was not fully investigated. The ability of VPA to inhibit HDAC has also been implicated as a 
potential mechanism of its teratogenicity (Gurvich et al., 2005; Menegola et al., 2005). Acetylation of histones leads to a relaxed chromatin structure where active transcription can occur and relaxation of chromatin can also lead to increased susceptibility to DNA damage (Carraway and Gore, 2007; Xu et al., 2007). Therefore in this present study, we investigated the potential role of HDAC inhibition in VPA-initiated HR.

First, to determine if VPA can inhibit HDAC in CHO 33 cells, histone acetylation status was assessed since inhibition of HDAC leads to acetylation of histones, so in this study, the levels of acetylated histone $\mathrm{H} 3$ and $\mathrm{H} 4$ were measured by immunoblotting after cells were exposure to $5 \mathrm{mM}$ VPA for 10, 16 or 24 hrs. An increase in the acetylation of these proteins was observed for all time points in the VPA treatment group. Furthermore, from our comparative recombination study with TSA, a known HDAC inhibitor and teratogen (Gurvich et al. 2005; Menegola et al., 2005), similar HR frequencies were observed between VPA and TSA treatment. Therefore from these studies, VPA was demonstrated to inhibit HDAC and inhibition of HDAC was shown to play a role in initiating HR.

HDAC inhibitors have a wide range of effects on cellular processes. In the nucleus, HDAC inhibitors have also been implicated to play a role in DNA DSBs repair. Following $24 \mathrm{hr}$ exposure to $200 \mathrm{nM}$ TSA, a panel of genes involved in HR repair have been shown to be down-regulated including; ataxia telangiectasia-related (ATM), Bloom's syndrome helicase, breast cancer 1 and -2 and Nijmegen breakage syndrome 1 (Nbs1) in a squamous carcinoma cell line (Zhang et al., 2007). Another key protein 
involved in homology search and strand invasion during HR, Rad51 has also been found to be down-regulated to one-third of its normal levels when treated with another broad spectrum HDAC inhibitor, PCI-24781 (Adimoolam et al., 2007). Inhibition of HR repair is thought to be a mechanism by which HDAC inhibitors sensitize cancer cells to radiation therapy. These studies are in contrast to our present study as well as our previous study where an increase in HR frequency was observed following exposure to VPA. However, chromatin changes as a result of histone acetylation/deacetylation have also been shown to play a critical role in initiating DNA DSB repair. TSA treatment has been demonstrated to induce rapid and localized phosphorylation of ATM kinase in human fibroblasts in the absence of DNA DSBs (Bakkenist and Kastan, 2003). Intermolecular autophosphorylation of ATM dimers leads to free active ATM monomers which can phosphorylate other proteins involved in HR such as Nbs1 and p53 to initiate repair (Bakkenist and Kastan, 2003). These opposing effects in HR repair reflect the complex functions of these inhibitory proteins and highlight the importance of posttranslational acetylation in cellular processes. In our present study, VPA seems to have a positive effect on initiating HR.

In addition, our recombination study also demonstrated that exposure to $5 \mathrm{mM}$ VPA for 24 hrs did not affect the repair activity of VPA-initiated HR when an artificial DNA DSB was induce in CHO 33 cells. Subsequently, from our proposed mechanism of VPA-initiated HR (Figure 1.9), we wanted to determine if VPA could increase the susceptibility to DNA DSBs to elicit repair. Following DNA DSB damage, an immediate 
target of ATM kinase is the histone H2A-variant, H2AX (Pandita and Richardson, 2009). Phosphorylation of $\mathrm{H} 2 \mathrm{AX}$ which is known as $\gamma-\mathrm{H} 2 \mathrm{AX}$, occurs within minutes of the damage (Pandita and Richardson, 2009). $\quad \gamma$-H2AX plays an important role in both DNA damage signalling and recruitment of DNA DSB repair proteins (Srivastava et al., 2009). In our VPA-induced DNA DSB study, $\gamma$-H2AX in the nucleus was visualized as discrete nuclear foci with each focus corresponding to one DNA DSB. At the same time points of our immunoblot experiment, $5 \mathrm{mM}$ VPA treatment caused a significant increase in the number of foci per cell which suggests that HDAC inhibition may play a potential role in VPA-induced DNA DSBs. HDAC inhibitors including TSA have been shown to alter chromatin structure by inhibiting HDACs that are responsible for deacetylating histones (Krajewski, 1999; Kuo and Allis, 1998; Yoshida, 1995). Hyperacetylation of histone and relaxation of chromatin structure as a result of HDAC inhibition may lead to increase susceptibility to DNA damage as observed in this study.

Consequently, to determine the mechanism behind VPA-induced DNA DSBs, our subsequent studies focused on oxidative stress and ROS, since previous studies have shown evidence of oxidative stress in VPA teratogenicity (Baran et al., 2005; Tabatabaei et al., 1999). Another recombination study was carried out in which CHO 33 cells were pretreated with PEG-catalase, an antioxidant, prior to VPA treatment. The observed protective effect of PEG-catalase against VPA-induced HR and the generation of intracellular ROS by VPA suggest ROS may also play a role in VPA-initiated HR. ROS can target various cellular components to cause damage and nuclear DNA has been 
demonstrated as a potential target of ROS generated by VPA (Tabatabaei et al., 1999). Therefore, a DNA oxidative damage study was carried out to determine if VPA-induced ROS production can cause oxidative DNA damage leading to DNA DSBs to initiate repair. However, in our DNA oxidation study, no increases in the oxidized nucleosides, 8-OH-2'-dG or 5-OH-C were observed after VPA treatment. In addition to causing damage to nucleosides, ROS can also react with the sugar moiety of DNA to cause DNA strand breaks (Spear and Aust, 1995) which was not measured in our study. However, oxidation of the sugar backbone is often accompanied by oxidation of nucleosides (Adam et al., 2001; Pisha et al., 2001; Spear and Aust, 1995), which suggests that DNA oxidative damage is not occurring after VPA treatment in our study.

In addition to causing cellular macromolecule damage, ROS can also alter endogenous ROS-mediated signal transduction pathways (Hansen, 2006). The increase in VPA-induced ROS observed in our study was relatively low (less than 2-fold increase compared to control) which may suggest VPA-induced ROS production may act on cell signalling rather than causing oxidative damage. Among the different $\mathrm{ROS}, \mathrm{H}_{2} \mathrm{O}_{2}$ is an important intracellular messenger which acts as a key signalling molecule in cell growth and differentiation (Sauer et al., 2001). Exposure to $\mathrm{H}_{2} \mathrm{O}_{2}$ can induce a number of genomic responses including the expression of p53 (Desaint et al., 2004). p53 is a tumour suppressor protein which functions to prevent the accumulation of mutations by restricting the proliferation of damaged cells and enhancing DNA repair or by inducing apoptosis (D'Autreaux and Toledano, 2007). Acting as a potent transcriptional 
activator/repressor, p53 can induce cell-cycle arrest (Liang et al., 2009). For example, in CHO cells, p53 can increase the expression of the growth arrest and DNA damage-45 alpha (GADD 45a) stress protein upon exposure to UV irradiation (Tzang et al., 1999). GADD $45 \alpha$ is thought to bind and inhibit the activity of cyclin B/cdc2 leading to G2 arrest (Jin et al., 2002). Furthermore, p53 can also act independent of transcription and localize directly to sites of DNA DSB damage and promote repair (Al Rashid et al., 2005).

In addition to initiating a genomic response to potential DNA damage, ROS can also lower the kinase activity of DNA-PKcs, a crucial protein involved in NHEJ (Boldogh et al., 2003). Even though NHEJ and HR repair are largely regulated by different phases of the cell cycle, there is compensatory activity if one repair pathway is impaired (Allen et al., 2002; Richardson and Jasin, 2000). For example, cells from DNA-PKcs-deficient severe combined immunodeficiency mice that are impaired in NHEJ show normal and compensatory levels of HR after ionizing radiation (Pluth et al., 2001). Interestingly, chromosome aberrations including incomplete chromatid exchange aberrations were seen in these cells with compensatory HR repair (Pluth et al., 2001). The role of ROS in both the increased expression of p53 in causing G2 arrest and the compensatory activity of HR repair as a result of decrease DNA-PKcs may provide an explanation for the increase in HR observed in our study in response to DNA DSBs.

In light of the DNA DSBs without any apparent oxidative DNA damage observed in our study, evidence show that VPA can up-regulate the expression of topoisomerase- 
II $\alpha$ and $\beta$ (Das et al., 2007). Topoisomerase-II $\alpha$ is essential for survival of proliferating cells and its concentration rises during periods of cell growth and peaks during the G2/M phase of the cell cycle (Deweese and Osheroff, 2009). These enzymes modulate different topological forms of DNA by removing torsional strain during transcription, cell replication and division (Deweese and Osheroff, 2009). In the process of removing DNA supercoiling, knots and tangles, a cleavage complex is formed whereby a DNA DSB is created in one of the DNA segments to allow for translocation of the second DNA segment through the cleaved DNA (Berger et al., 1996). Although these enzymes are essential for cell viability, they also have the potential to fragment the genome (Deweese and Osheroff, 2009). When nucleic acid tracking systems, such as a replication or transcription complexes, attempt to traverse the cleavage complex, they can convert the enzyme-DNA interaction into a permanent DSB in the genome (Fortune and Osheroff, 2000). Therefore any changes in topoisomerase-II activity and/or protein expression can enhance the formation of DNA DSBs (Wang, 2002). The increased expression of topoisomerase-II by VPA may lead to the DNA DSBs observed our study in the absence of oxidative DNA damage.

In addition to modulating the expression of the different genes aforementioned, the HDAC inhibitor, TSA, has also been shown to cause a direct increase in GADD45 $\alpha$ expression through the transcription factors, octamer binding transcription factor 1 (Oct1) and nuclear factor $\mathrm{Y}$ on Oct-1 and CCAAT promoter binding sites respectively, independent of p53 activation (Hirose et al., 2003). Over-expression of GADD45 $\alpha$ can 
lead to growth arrest (Hollander and Fornace, 2002), so the HDAC inhibitory effects of VPA have the potential to indirectly cause both DNA DSBs and cell cycle arrest allowing repair.

\subsection{Future Directions}

In our present study, an increase in DNA DSBs was observed although no oxidative DNA was detected, consistent with a previous study from our laboratory (Defoort et al., 2006). The role of VPA-induced ROS and HDAC inhibition in initiating DNA DSBs and repair remains unclear. Examining the expression of proteins including ATM kinase, p53, GADD45 $\alpha$, DNA-PKs and topoisomerase-II $\alpha$ during VPA-initiated HR may provide further information in revealing the distinct roles of ROS signalling and HDAC inhibition in causing DNA DSBs and HR repair.

Other types of DNA damage can also lead to DNA DSBs, so it would be beneficial to investigate the potential for VPA reactive metabolites to enter the nucleus and bind to DNA. Radiolabelling VPA for liquid scintillation counting can be used to determine if VPA reactive metabolites can cause DNA adducts.

Future in vivo studies would also provide important developmental insights in the role of increase HR in VPA-induced teratogenesis. Animal models including the pKZ1 (Sykes et al., 1999) and fluorescent yellow direct-repeat mice (Hendricks et al., 2003) can be used to detect recombination events in specific embryonic tissues during development when exposed to VPA. Measuring DNA DBSs and correlating these results 
wirh acetylated histone $\mathrm{H} 3$ and $\mathrm{H} 4$ levels as well as the proteins aforementioned would also verify and clarify the role of ROS signalling and HDAC inhibition in VPA-induced teratogenesis. To determine specific chromosome aberrations, fluorescence in situ hybridization can be used to detect and localize the presence or absence of specific DNA sequences on chromosomes. In common regions of genomic rearrangements, specific genes can be identified to determine if they play a role during development such as neural tube formation.

\subsection{Conclusion}

In summary, the results of this study suggest a potential role of VPA-induced HDAC inhibition and ROS production in playing a role in VPA-initiated HR in CHO 33 cells. In addition, these results demonstrate that VPA does not affect HR repair activity but rather causes DNA DSBs to initiate repair. Although VPA induces a state of oxidative stress in this cell line, oxidative DNA damage was not observed. Therefore, further analysis is required to determine the effects of HDAC inhibition and ROS signalling in generating DNA DSBs and HR repair to elucidate the mechanism of VPAinitiated HR. 


\subsection{Significance}

Given that many pregnant women who have epilepsy take antiepileptic therapy and VPA is the principle drug for first-line treatment particularly for juvenile myoclonic epilepsy that develops in young adults of child bearing age (Genton et al., 2006), understanding the teratogenic mechanism of VPA will allow for the development of potential therapeutic strategies to reduce birth defects. Elucidating the mechanism of VPA induced birth defects may also provide a working model of how present or future teratogenic agents can cause toxicity in utero. 


\section{References}

Abdul, M. and Hoosein, N. (2001) Inhibition by anticonvulsants of prostate specific antigen and interleukin-6 secretion by human prostate cancer cells. Anticancer Res. 21, 2045-2048.

Adad, N. et al. (2004) The longer term outcome of children born to mothers with epilepsy. J. Neurol. Neurosurg. Psych. 75, 1575-1583.

Adam, W., Arnold, M.A., Nau, W.M., Pischel, U., Saha-Moller, C.R. (2001) Structuredependent reactivity of oxyfunctionalized acetophenones in the photooxidation of DNA: base oxidation and strand breaks through photolytic radical formation (spin trapping, EPR spectroscopy, transient kinetics) versus photosensitization (electron transfer, hydrogen-atom abstraction). Nucleic Acids Res. 29, 4955-4962.

Adimoolam, S., Sirisawad, M., Chen, J., Thiemann, P., Ford, J.M., Buggy, J.J. (2007) HDAC inhibitor PCI-24781 decreases RAD51 expression and inhibits homologous recombination. Proc. Natl. Acad. Sci. USA.104, 19482-19487.

Al Rashid, S.T. et al. (2005) Evidence for the direct binding of phosphorylated p53 to sites of DNA breaks in vivo. Cancer Res. 65, 10810-10821.

Allen, C., Kurimasa, A., Brenneman, M.A., Chen, D.J., Nickoloff, J.A. (2002) DNAdependent protein kinase suppresses double-strand break-induced and spontaneous homologous recombination. Proc. Natl. Acad. Sci. USA. 19, 3758-3763.

Amini, S.A. et al. (1996) Oxidative stress and the fetotoxicity of alcohol consumption during pregnancy. Free Radic. Biol. Med. 21, 357-365.

Andersen, G.O. and Ritland, S. (1995) Life threatening intoxication with sodium valproate. J. Toxicol. Clin. Toxicol. 33, 279-284.

Arnaudeau,C., Helleday,T. and Jenssen,D. (1999) The RAD51 protein supports homologous recombination by an exchange mechanism in mammalian cells. J. Mol. Biol. 289, 1231-1238.

Asconape, J.J., Penry, J.K., Dreifuss, F.E., Riela, A., Mirza, W. (1993) Valproateassociated pancreatitis. Epilepsia. 34, 177-183.

Bakkenist, C.J. and Kastan, M.B. (2003) DNA damage activates ATM through intermolecular autophosphorylation and dimer dissociation. Nature. 421, 499-506. 
Baran, O., Nergiz, Y., Tuncer, M.C. (2005) The effects of valproic acid, vitamin E and folic acid on ribs of fat foetuses in the prenatal period. Ann. Anat. 188, 117-125.

Battino, D. and Tomson, T. (2007) Management of epilepsy during pregnancy. Drugs. 6, 2727-2746.

Bazinet, R. P., Weis, M. T., Rapoport, S. I., Rosenberger, T. A. (2006) Valproic acid selectively inhibits conversion of arachidonic acid to arachidonoyl-CoA by brain microsomal long-chain fatty acyl-CoA synthetases: relevance to bipolar disorder. Psychopharmacology (Berl.). 184, 122 - 129.

Berger, J.M., Gamblin, S.J., Harrison, S.C., Wang J.C. (1996) Structure and mechanism of DNA topoisomerase II. Nature. 379, 225-232.

Bishop, A.J.R. and Schiesti, R.H. (2003) Role of homologous recombination in carcinogenesis. Exp. Mol. Pathol. 74, 94-105.

Bjoras, M. et al. (1997) Opposite base-dependent reactions of a human base excision repair enzyme on DNA containing 7,8-dihydro-8-oxoguanine and abasic sites. EMBO J. 16, 6314-6322.

Boldogh, I. et al. (2003) Reduced DNA double strand breaks in chlorambucil resistant cells are related to high DNA-PKcs activity and low oxidative stress. Toxicology. 193, 137-152.

Bolin, C., Stedeford, T., Cardozo-Pelaez, F. (1995) Single extraction protocol for the analysis of 8-hydroxy-2'-deoxyguanosine (oxo8dG) and the associated activity of 8oxoguanine DNA glycosylase. J. Neurosci. Methods. 136, 69-76.

Bryant, A.E., $3^{\text {rd }}$. and Dreifuss, F.E. (1986) Valproic acid hepatic fatalities. III. U.S. experience since 1986. Neurology. 46, 465-469.

Burton, B.S. (1882) On the propyl derivatives and decomposition products of ethylacetoacetate. Am. Chem. J. 3, 385-395.

Camargo, S.E. et al. (2009) Cytotoxicity and genotoxicity of pulp capping materials in two cell lines. Int. Endod. J. 42, 227-237.

Camfield, P.R., Bagnell, P., Camfield, C.S., Tibbles, J.A.R. (1979) Pancreatitis due to valproic acid. Lancet. 1, 1198-9.

Carraway, H.E. and Gore, S.D. (2007) Addition of histone deacetylase inhibitors in combination therapy. J. Clin. Oncol. 25, 1955-1956. 
Catalano, M.G. et al. (2006) Valproic acid, a histone deacetylase inhibitor, enhances sensitivity to doxorubicin in anaplastic thyroid cancer cells. J. Endocrinol. 191, 465-472.

Chang, T.K.H. and Abbot, F.S. (2006) Oxidative stress as a mechanism of valproic acidassociated hepatotoxicity. Drug Metab. Rev. 38, 627-639.

Chen, P.S. et al. (2007) Valproic acid and other histone deacetylase inhibitors induce microglial apoptosis and attenuate lipopolysaccharide-induced dopaminergic neurotoxicity. Neuroscience. 149, 203-212.

Coulter, D. L. (1984) Carnitine deficiency: a possible mechanism for valproate hepatotoxicity. Lancet. 1, p. 689.

Das, C.M. et al. (2007) Valproic acid induces p21 and topoisomerase-II (alpha/beta) expression and synergistically enhances etoposide cytotoxicity in human glioblastoma cell lines. J. Neurooncol. 85, 159-170.

D’Autreaux, B. and Toledano, M.B. (2007) ROS as signalling molecules: mechanisms that generate specificity in ROS homeostasis. Nat. Rev. Mol. Cell Biol. 8, 813-824.

Defoort, E.N., Kim, P.M., Winn, L.M. (2006) Valproic acid increases conservative homologous recombination frequency and reactive oxygen species formation: a potential mechanism for valproic acid-induced neural tube defects. Mol. Pharmacol. 69, 13041310.

Desaint, S., Luriau, S., Aude, J-C., Rousselet, G., Toledano, M.B. (2004) Mammalian antioxidant defenses are not inducible by $\mathrm{H}_{2} \mathrm{O}_{2}$. J. Biol. Chem. 279, 31157-31163.

Deweese, J.E. and Osheroff, N. (2009) The DNA cleavage reaction of topoisomerase II: wolf in sheep's clothing. Nucleic Acids Res. 37, 738-748.

Dickinson, R.G., Harland, R.C., Lynn, R.K., Smith, W.B., Gerber, N. (1979) Transmission of valproic acid (Depakene) across the placenta: half-life of the drug in mother and baby. J. Pediatr. 94, 832-835.

Duenas-Gonzalez, A. et al. (2008) Valproic acid as epigenetic cancer drug: preclinical, clinical and transcriptional effects on solid tumors. Cancer Treat. Rev. 34, 206-222.

Eriksson, K., Viinikainen, K., Monkkonen, A., Aikia, M., Nieminen, P., Heinonen, S. (2005) Children exposed to valproate in utero-population based evaluation of risk and confounding factors for long-term neurocognitive development. Epilepsy Res. 65, 189200.

Fortune, J.M and Osheroff, N. (2000) Topoisomerase II as a target for anticancer drugs: when enzymes stop being nice. Prog. Nucleic Acid Res. Mol. Biol. 64, 221-253. 
Franssen, E.J. et al. (1999) Valproic acid toxicokinetics: Serial hemodialysis and hemoperfusion. Ther. Drug Monit. 21, 289-292.

Froescher, W., Gugler, R., Niesen, M., Hoffmann, F. (1984) Protein binding of valproic acid in maternal and umbilical cord serum. Epilepsia. 25, 244-249.

Fromenty, B. and Pessayre, D. (1997) Impaired mitochondrial function in microvesicular steatosis. Effects of drugs, ethanol, hormones and cytokines. J. Hepatol. 26, 43-53.

Fukuchi, K., Martin, G.M., Monnat, Jr, R.J. (1989) Mutator phenotype of Werner syndrome is characterized by extensive deletions. Proc. Natl. Acad. Sci. USA. 86, 58935897.

Genton, P., Semah, F., Trinka, E. (2006) Valproic acid in epilepsy: pregnancy-related issues. Drug Saf. 29, 1-21.

German, J. (1995) Bloom's syndrome. Dermatologic Clinics. 13, 7-18.

Graf, W. D., Oleinik, O. E., Glauser, T. A., Maertens, P., Eder, D. N., Pippenger, C. E. (1998). Altered antioxidant enzyme activities in children with a serious adverse experience related to valproic acid therapy. Neuropediatrics. 29, 195-201.

Gurvich, N. et al. (2005) Association of valproate-induced teratogenesis with histone deacetylase inhibition in vivo. FASEB J. 19, 1166-1168.

Hamed, S.A, Abdellah, M.M., El-Melegy, N. (2004) Blood levels of trace elements, electrolytes, and oxidative stress/antioxidant systems in epileptic patients. J. Pharmacol. Sci. 96, 465-473.

Hansen, J.M. (2006) Oxidative stress as a mechanism of teratogenesis. Birth Defects Res. C Embryo Today. 78, 308-325.

Hansen, J.M., Harris, K.K., Philbert, M.A., Harris, C. (2002) Thalidomide modulates nuclear redox status and preferentially depletes glutathione in rabbit limb versus rat limb. J. Pharmacol. Exp. Ther. 300, 768-776.

Hendricks, C.A. et al. (2003) Spontaneous mitotic homologous recombination at an enhanced yellow fluorescent protein (EYFP) cDNA direct repeat in transgenic mice. Proc. Natl. Acad. Sci. USA. 100, 6325-6330.

Hiilesmaa, V.K., Bardy, A., Teramo, K. (1985) Obstetric outcome in women with epilepsy. Am. J. Obstet. Gynecol. 152, 499-504. 
Hill, J.W., Hazra, T.K., Izumi, T., Mitra, S. (2001) Stimulation of human 8-oxoguanineDNA glycosylase by AP-endonuclease: potential coordination of the initial steps in base excision repair. Nucleic Acids Res. 29, 430-438.

Hirose, T. et al. (2003) p53-independent induction of Gadd45 by histone deacetylase inhibitor: coordinate regulation by transcription factors Oct-1 and NF-Y. Oncogene. 22, 7762-7773.

Hollander, M.C. and Fornace A.J. Jr. (2002) Genomic instability, centrosome amplification, cell cycle checkpoints and Gadd45a. Oncogene. 21, 6228-6233.

Holmes, L.B. (2002) Teratogen-induced limb defects. Am. J. Med. Genet. 112, 297-303.

Huang, X., Powell, J., Mooney, L.A., Li, C., Frenkel, K. (2001) Importance of complete DNA digestion in minimizing variability of 8-oxo-dG analyses. Free Radic. Biol. Med. 31,1341-1351.

Jakobs, C. and Loscher, W. (1978) Identification of metabolites of valproic acid in serum of humans, dog, rat and mouse. Epilepsia. 19, 591-602.

Jin, S. et al. (2002) GADD45-induced cell cycle G2-M arrest associates with altered subcellular distribution of cyclin B1 and is independent of p38 kinase activity. 21, 86968704.

Joenje, H. and Patel, K.J. (2001) The emerging genetic and molecular basis of Fanconi anaemia, Nat. Rev. Genet. 2, 446-457.

Johnstone, R.W. (2002) Histone-deacetylase inhibitors: novel drugs for the treatment of cancer. Nat. Rev. Drug Discov. 1, 287-299.

Kawagoe, R., Kawagoe, H., Sano, K. (2002) Valproic acid induces apoptosis inhuman leukaemia cells by stimulating both caspase-dependent and -independent apoptotic signalling pathways. Leukemia Res. 26, 495-502.

Kesterson, J. W., Granneman, G. R., Machinist, J. M. (1984) The hepatotoxicity of valproic acid and its metabolites in rats. I. Toxicologic, biochemical and histopathologic studies. Hepatology 4, 1143-1152.

Kini, U. (2006) Fetal valproate syndrome: a review. Pediatr. Perninatal. Drug Ther. 7, 123-130.

Kishi, T. et al. (1994) Bone marrow suppression induced by high dose valproic acid. Arch. Dis. Child. 71, 153-155. 
Klotz, U. and Antonin, K.H. (1977) Pharmacokinetics and bioavailability of sodium valproate. Clin. Pharm. Ther. 21, 736-743.

Knudson, A.G. (2001) Two genetic hits (more or less) to cancer. Nat. Rev. Cancer. 1, 157-162.

Kohen, R. and Nyska, A. (2002) Oxidation of biological systems: oxidative stress phenomena, antioxidants, redox reactions, and methods for their quantification. Toxicol. Pathol. 30, 620-650.

Konig, S. A. et al. (1999) Fetal liver failure associated with valproate therapy in a patient with Friedreich's disease: review of valproate hepatotoxicity in adults. Epilepsia. 40, 1036-1040.

Koren, G., Nava-Ocampo, A.A., Moretti, M.E., Sussman, R, Nulman, I. (2006) Major malformations with valproic acid. Can. Fam. Phys. 52, 441-447.

Kossak, B. D., Schmidt-Sommerfeld, E., Schoeller, D. A., Rinaldo, P., Penn, D., Tonsgard, J. H. (1993) Impaired fatty acid oxidation in children on valproic acid and the effect of L-carnitine. Neurology. 43, 2362-2368.

Kottlors, M, Jaksch, M., Ketelsen, U.P., Weiner, S., Glocker, F.X., Lucking, C.H. (2001) Valproic acid triggers acute rhabdomyolysis in a patient with carnitine palmitoyltransferase type II deficiency. Neuromuscular Disord. 11, 757-759.

Krajewski, W.A. (1999) Effect of in vivo histone hyperacetylation on the state of chromatin fibers. J. Biomol. Struct. Dyn. 16, 1097-1106.

Kuo, M.H. and Allis, C.D. (1998) Roles of histone acetyltransferases and deacetylases in gene regulation. Bioessays. 20, 615-626.

Leng, Y. and Chuang, D.M. (2006) Endogenous alpha-synuclein is induced by valproic acid through histone deacetylase inhibition and participates in neuroprotection against glutamate-induced excitotoxicity. J. Neurosci. 26, 7502-7512.

Lheureux, P.E., Penaloza, A., Zahir, S., Gris, M. (2005) Science review: carnitine in the treatment of valproic acid-induced toxicity- what is the evidence? Crit. Care. 9, 431-440.

Li, Y. et al. (2008) Prevention of hypoxia-induced neuronal apoptosis through histone deacetylase inhibition. J. Trauma. 64, 863-870. 
Liang, Y., Lin, S.Y., Brunicardi, F.C., Goss, J., Li, K. (2009) DNA damage response pathways in tumor suppression and cancer treatment. World J. Surg. 33, 661-666.

Lim, D-S. and Hasty, P. (1996) A mutation in mouse Rad51 results in an early embryonic lethal that is suppressed by a mutation in p53. Mol. Cell Biol. 16, 7133-7143.

Lindahl, T. and Wood, R.D. (1999) Quality control by DNA repair. Science. 286, 18971905.

Liu, L., Maguire, K.K., Kmiec, E.B. (2004) Genetic re-engineering of Saccharomyces cerevisiae RAD51 leads to a significant increase in the frequency of gene repair in vivo. Nucleic Acids Res. 32, 2093-2101.

Ludwig, T., Chapman, D.L., Papaioannou, V.E., Efstratiadis, A. (1997) Targeted mutations of breast cancer susceptibility gene homologs in mice: lethal phenotypes of Brca1, Brca2, Brca1/2, Brca1/p53, and Brca2/p53 nullizygous embryos. Genes Dev. 11, 1226-1241.

McLean, M.J. and MacDonald, R.L. (1986). Sodium valproate, but not ethosuximide, produces use- and voltage-dependent limitation of high frequency repetitive firing of action potentials of mouse central neurons in cell culture. J. Pharmacol. Exp. Ther. 237, 1001-1011.

Menegola, E. et al. (2005) Inhibition of histone deacetylase activity on specific embryonic tissues as a new mechanism for teratogenicity. Birth Defects Res. B Dev. Reprod. Toxicol. 74, 392-398.

Meunier, H., Carraz, G., Neunier, Y., Eymard, P., Aimard, M. (1962) Propriétés pharmacodynamiques de l'aciden-dipropylacetique. Therapie. 18, 435-438.

Michoulas, A., Tong, V., Teng, X.W., Chang, T.K.H., Abbott, F.S., Farrell, K. (2006) Oxidative stress in children receiving valproic acid. J. Pediatr. 149, 692-696.

Moore, S.J. et al. (2000) A clinical study of 57 children with fetal anticonvulsant syndromes. J. Med. Genet. 37, 489-497.

Na, L., Wartenberg, M., Nau, H., Hescheler, J., Sauer, H. (2003) Anticonvulsant valproic acid inhibits cardiomyocyte differentiation of embryonic stem cells by increasing intracellular levels of reactive oxygen species. Birth Defects Res. 67, 174-180.

Nakamura, H. et al. (2002) Proton gradient-dependent transport of valproic acid in human placental brush border membrane vesicles. Pharm. Res. 19, 154-61. 
Nau, H. and Loscher, W. (1984) Valproic acid and metabolites: Pharmacological and toxicological studies. Epilepsia. 25, S14-S22.

Nau, H. and Loscher, W. (1986) Pharmacologic evaluation of various metabolites and analogs of valproic acid: teratogenic potencies in mice. Fundam. Appl. Toxicol. 6, 669676.

Nau, H., Rating, D., Koch, S., Hauser, I., Helge, H. (1981) Valproic acid and its metabolites: placenta transfer, neonatal pharmacokinetics, transfer via mother's milk and clinical status in neonates of epileptic mothers. Pharm. Exp. Ther. 219, 768-777.

Nau, H. and Wittfoht, W. (1981) Quantitative determination in serum, urine, breast milk and tissues by gas chromatography mass spectrometry using selected ion monitoring. $J$. Chromatogr. 226, 69-78.

Nelson-DeGrave, V.L. et al. (2004) Valproate potentiates androgen biosynthesis in human ovarian theca cells. Endocrinology 145, 799-808.

Nouspikel, T. (2009) DNA repair in mammalian cells: Nucleotide excision repair: variations on versatility. Cell Mol. Life Sci. 66, 994-1009.

Olsen, C.M., Meussen-Elhom, E.T.M, Roste, L.S., Tauboll, E. (2004) Antiepileptic drugs inhibit cell growth in the human breast cancer cell line MCF-7. Mol. Cell Endocrinol. 213, 173-179.

Ornoy, A. (2007) Embryonic oxidative stress as a mechanism of teratogenesis with special emphasis on diabetic embryopathy. Reprod. Toxicol. 24, 31-41.

Owens, M.J., Nemeroff, C.B. (2003) Pharmacology of valproate. Psychopharmacol Bulletin. 37(S2), 17-24.

Pandita, T.K. and Richardson, C. (2009) Chromatin remodeling finds its place in the DNA double-strand break response. Nucleic Acids Res. 37, 1363-1377.

Papadimitriou, A. and Servidei, S. (1991) Late onset lipid storage myopathy due to multiple acyl-CoA dehydrogenase deficiency triggered by valproate. Neuromuscular Disord. 1, 247-252.

Pardo, B., Gomez-Gonzalez, B., Aquilera, A. (2009) DNA repair in mammalian cells: DNA double-strand break repair: how to fix a broken relationship. Cell Mol. Life Sci. 66, 1039-1056. 
Park, M.S. (1995) Expression of human RAD52 confers resistance to ionizing radiation in mammalian cells. J. Biol. Chem., 270, 15467-15470

Parman, T., Chen, G., Wells, P. G. (1998) Free radical intermediates of phenytoin and related teratogens. Prostaglandin $\mathrm{H}$ synthase-catalyzed bioactivation, electron paramagnetic resonance spectrometry, and photochemical product analysis. J. Bio. Chem. 273, 25079-25088.

Pennell, PB., Gidal, B.E., Sabers, A., Gordon, J., Perucca, E. (2007) Pharmacology of antiepileptic drugs during pregnancy and lactation. Epilepsy Behav. 11, 263-269.

Perucca, E. (2002) Pharmacological and therapeutic properties of valproate. CNS Drugs. 16, 695-714.

Pfeiffer, P., Goedecke, W., Obe, G. (2000) Mechanisms of DNA double-strand break repair and their potential to induce chromosomal aberrations. Mutagenesis. 15, 289-302.

Pinkston, R. and Walker, L.A. (1997) Multiorgan system failure caused by valproic acid toxicity. Am. J. Em. Med. 15, 504-506.

Pisha, E., Lui, X., Constantinou, A.I., Bolton, J.L. (2001) Evidence that a metabolite of equine estrogens, 4-hydroxyequilenin, induces cellular transformation in vitro. Chem. Res. Toxicol. 14, 82-90.

Pluth, J.M., Fried, L.M., Kirchgessner, C.U. (2001) Severe combined immunodeficient cells expressing mutant hRAD54 exhibit a marked DNA double-strand break repair and error-prone chromosome repair defect. Cancer Res. 61, 2649-2655.

Ponchault, S., van Hoof, F., Veitch, K. (1992) In vitro effects of valproate and valproate metabolites on mitochondrial oxidations: relevance of CoA sequestration to the observed inhibitions. Biochem. Pharmacol. 43, 2435-2442.

Powell-Jackson, P.R., Tredger, J.M., Williams, R. (1984) Hepatotoxicity to sodium valproate: a review. Gut. 25, 673-681.

Reliene, R., Bishop, A.J., Schiestl, R.H. (2007) Involvement of homologous recombination in carcinogenesis. Adv. Genet. 58, 67-87.

Richardson, C. and Jasin, M. (2000) Coupled homologous and nonhomologous repair of a double-strand break preserves genomic integrity in mammalian cells. Mol. Cell Bio. 20, 9068-9075. 
Rosenquist, T.A., Zharkov, D.O., Grollman, A.P. (1997) Cloning and characterization of a mammalian 8-oxoguanine DNA glycosylase. Proc. Natl. Acad. Sci. USA. 94, 74297434.

Russell, S. (2007) Carnitine as an antidote for acute valproate toxicity in children. Curr Op. Pediatr. 19, 206-210.

Sauer, H., Wartenberg, M., Hescheler, J. (2001) Reactive oxygen species as intracellular messengers during cell growth and differentiation. Cell Physiol. Biochem. 11, 173-186.

Scheffner, D., Konig, S., Rauterberg-Ruland, I., Kochen, W., Hofmann, W.J., Unkelbach, S. (1988) Fatal liver failure in 16 children with valproate therapy. Epilepsia. 29, 530-42.

Seckin, S., Basaran-Kucukgergin, C., Uysal, M. (1999) Effect of acute and chronic administration of sodium valproate on lipid peroxidation and antioxidant system in rat liver. Pharmacol. Toxicol. 85, 294-298.

Shaltiel, G. et al. (2004) Valproate decreases inositol biosynthesis. Biol. Psychiatry. 56, 868-874.

Shrivastav, M., De Haro, L.P., Nickoloff, J.A. (2007) Regulation of DNA double-strand break repair pathway choice. Cell Res. 18, 134-147.

Silva, M.F.B. et al. (2001a) Differential effect of valproate and its D2- and D4unsaturated metabolites, on the b-oxidation rate of long-chain and medium-chain fatty acids. Chem-Biol. Interact. 137, 203-212.

Silva, M.F.B. et al (2001b) Synthesis and intramitochondrial levels of valproyl-CoA metabolites. Anal. Biochem. 290, 60-67.

Silverstone, P. H., McGrath,B. M., Kim, H. (2005) Bipolar disorder and myo-inositol: a review of the magnetic resonance spectroscopy findings. Bipolar Disord. 7, 1-10.

Sodhi, P., Banani, P., Parmar, V. (2001) Fatal cardiac malformation in fetal valproate syndrome. Indi. J. Pediatr. 68, 989-990.

Spear, N. and Aust, S.D. (1995) Effects of glutathione on Fenton reagent-dependent radical production and DNA oxidation. Arch. Biochem. Biophys. 324, 111-116.

Srivastava, N., Gochhait, S., de Boer, P, Bamezai, R.N. (2009) Role of H2AX in DNA damage response and human cancers. Mutat. Res. 681, 180-188. 
Sykes, P.J., Hooker, A.M., Morley, A.A. (1999) Inversion due to intrachromosomal recombination produced by carcinogens in a transgenic mouse model. Mutat. Res. 427, 19 .

Sztajnkrycer, M.D. (2002) Valproic acid toxicity: Overview and management. J. ToxClin. Tox. 40, 789-801.

Tabatabaei, A.R., Thies, R.L., Abbott, F.S. (1999) Assessing the mechanism of metabolism dependent valproic acid-induced in vitro cytotoxicity. Chem. Res. Toxicol. 12, 323-330.

Taghian, D.G. and Nickoloff, J.A. (1997) Chromosomal double-strand breaks induce gene conversion at high frequency in mammalian cells. Mol. Cell Biol. 17, 6386-6393.

Tatsuhara, T., Muro, H., Matsuda, Y., Imai, Y. (1987) Determination of valproic acid and its metabolites by gas chromatography mass spectrometry with selected ion monitoring. J. Chromatogr. 399, 183-195.

Tebbs, R.S., Meneses, J.J., Flannery, M., Thompson, L.H., Cleaver, J.E., Pederson, R.A. (1997) Requirement for the XRCC1 DNA base excision repair gene during early mouse development. Dev. Biol. 208, 513-529.

Teramo, K., Hiilesmaa, V., Bardy, A., Saarikoski, S. (1979) Fetal heart rate during a maternal grand mal epileptic seizure. J. Perinat. Med. 7, 3-6.

Tzang, B.S. et al. (1999) Function and sequence analyses of tumor suppressor gene p53 of CHO.K1 cells. DNA Cell Biol. 18, 315-321.

Van den Berg, C.J., Kok, P., Voskuyl, R.A. (1993) Valproate and sodium currents in culture hippocampal neurons. Exp. Brain Res. 93, 279-287.

van den Bosch, M., Lohman, P.H.M., Pastink, A. (2002) DNA double-strand break repair by homologous recombination. Biol. Chem. 383, 873-892.

Vavrova, J., Rezacova, M., Osterreicher, J. (2005) Inhibitors of histone-deacetylase. J. Appl. Biomed. 3, 115-121.

Vispe, S., Cazaux, C., Lesca, C., Defais, M. (1998) Overexpression of Rad51 protein stimulates homologous recombination and increases resistance of mammalian cells to ionizing radiation. Nucleic Acids Res. 26, 2859-2864.

Wang, J.C. (2002) Cellular roles of DNA topoisomerases: a molecular perspective. Nat. Rev. Mol. Cell Biol. 3, 430-440. 
Wells, P.G., Kim, P.M., Laposa, R.R., Nicol, C.J., Parman T., Winn, L.M., (1997) Oxidative damage in chemical teratogenesis. Mutat. Res. 396, 65-78.

Wells, P.G. et al. (2005) Molecular and biochemical mechanisms in teratogenesis involving reactive oxygen species. Toxicol Appl. Pharmacol. 207(S2), 354-366.

Williams, D.C. Jr., Massey, G.V., Russell, E.C., Riley. R.S., Ben-Ezra, J. (2008) Translocation-positive acute leukemia associated with valproic acid therapy. Pediatr. Blood Cancer. 50, 641-643.

Winn, L.M. and Wells, P.G. (1997) Evidence for embryonic prostaglandin H synthasecatalyzed bioactivation and reactive oxygen species-mediated oxidation of cellular macromolecules in phenytoin and benzo[a]pyrene teratogenesis. Free Radic. Biol. Med. 22, 607-621.

Winn, L.M., Wells, P.G. (1999) Maternal administration of superoxide dismutase and catalase in phenytoin teratogenicity. Free Radic. Biol. Med. 26, 266-274

Xu, W.S., Parmigiani, R.B., Marks, P.A. (2007). Histone deacetylase inhibitors: molecular mechanisms of action. Oncogene. 13, 5541-5552.

Yoshida, M., Horinouchi, S., Beppu, T. (1995) Trichostatin A and trapoxin: novel chemical probes for the role of histone acetylation in chromatin structure and function. Bioessays. 17, 423-430.

Zafrani, E. S. and Berthelot, P. (1982) Sodium valproate in the induction of unusual hepatotoxicity. Hepatology. 2, 648-649.

Zhang, Y., Carr, T., Dimtchev, A., Zare, N., Dritschilo, A., Jung, M. (2007) Attenuated DNA damage repair by trichostatin A through BRCA1 suppression. Radiat. Res. 168, 115-124.

Zimmerman, H. J. and Ishak, K. G. (1982) Valproate-induced hepatic injury: analysis of 23 fatal cases. Hepatology. 2, 591-597. 